\title{
Electrochromic Radiator Coupon Level Testing and Full Scale Thermal Math Modeling for Use on Altair Lunar Lander
}

\author{
Erika T. Bannon ${ }^{1}$ and Chad E. Bower ${ }^{2}$ \\ Paragon Space Development Corporation, Tucson, AZ, 85714 \\ and \\ Rubik Sheth ${ }^{3}$ and Ryan Stephan ${ }^{4}$ \\ NASA Johnson Space Center, Houston, TX, 77058
}

\begin{abstract}
In order to control system and component temperatures, many spacecraft thermal control systems use a radiator coupled with a pumped fluid loop to reject waste heat from the vehicle. Since heat loads and radiation environments can vary considerably according to mission phase, the thermal control system must be able to vary the heat rejection. The ability to "turn down" the heat rejected from the thermal control system is critically important when designing the system. Electrochromic technology as a radiator coating is being investigated to vary the amount of heat rejected by a radiator. Coupon level tests were performed to test the feasibility of this technology. Furthermore, thermal math models were developed to better understand the turndown ratios required by full scale radiator architectures to handle the various operation scenarios encountered during a mission profile for the Altair Lunar Lander. This paper summarizes results from coupon level tests as well as the thermal math models developed to investigate how electrochromics can be used to increase turn down ratios for a radiator. Data from the various design concepts of radiators and their architectures are outlined. Recommendations are made on which electrochromic radiator concept should be carried further for future thermal vacuum testing.
\end{abstract}

\section{Nomenclature}

$\begin{array}{ll}A & =\text { area of the radiator } \\ \varepsilon & =\text { emissivity of the surface of the radiator } \\ \alpha & =\text { solar absorptivity } \\ \sigma & =\text { Stefan-Boltzmann constant } \\ T_{\text {surface }} & =\text { temperature of the surface of the radiator } \\ T_{\text {sink }} & =\text { temperature of the sink the radiator sees } \\ \mathrm{RHX} & =\text { Regenerative Heat exchanger } \\ \mathrm{Q}_{\text {losses }} & =\text { Energy Losses } \\ \mathrm{V} & =\text { Voltage } \\ \mathrm{I} & =\text { Current } \\ \varepsilon_{\text {high }} & =\text { High emissivity state } \\ \varepsilon_{\text {low }} & =\text { Low emissivity state } \\ \mathrm{A}_{\mathrm{A}} & =\text { Electrochromic Active Area } \\ \mathrm{Q}_{\text {high }} & =\text { High temperature test point energy applied } \\ \mathrm{Q}_{\text {low }} & =\text { Low temperature test point energy applied }\end{array}$

${ }^{1}$ Research and Development Engineer, 3481 E. Michigan Street, and AIAA Member Grade for first author.

${ }^{2}$ Senior Thermal Analyst, 3481 E. Michigan Street, and AIAA

${ }^{3}$ Thermal Systems Engineer, 2101 Nasa Road 1 EC2, and AIAA Member Grade for fourth author.

${ }^{4}$ Exportation Technology Development Program Thermal Project Manager, 2101 Nasa Road 1 EC1, and AIAA Member Grade for fourth author. 


\section{Introduction}

Spacecraft for NASA's Altair Lunar Lander will have a considerable variation in waste heat rejection as well as Sexposure to various sink temperatures on the way to and at the moon. Radiators are the best thermal control devices for long term heat rejection, but both the heat loads and the local radiation environments are expected to vary considerably. For example, during lunar transit the radiators are expected to reject a heat load of $\sim 900$ Watts to a $\sim 70 \mathrm{~K}$ sink temperature. On the other hand during surface operations the radiator is expected to reject about six kilowatts of heat at a sink temperature of $\sim 215 \mathrm{~K}$. The various heat rejection requirements as well as sink temperature environments can be seen in Figure 1 for a radiator emissivity of 0.85 and absorptivity of 0.1 .

Radiators reject waste heat by radiation heat transfer with the environment. The waste heat is supplied to the radiator either by a fluid loop or by conduction from electronics mounted directly on it. Radiator temperatures must consequently be controlled to stay within the limits of the components in contact with it. This can be difficult if either the radiation environment or the heat rejection loads vary much. Typically, radiators are sized for the largest constant heat rejection requirement at the highest sink temperature. Due to this design point, a radiator's working fluid is

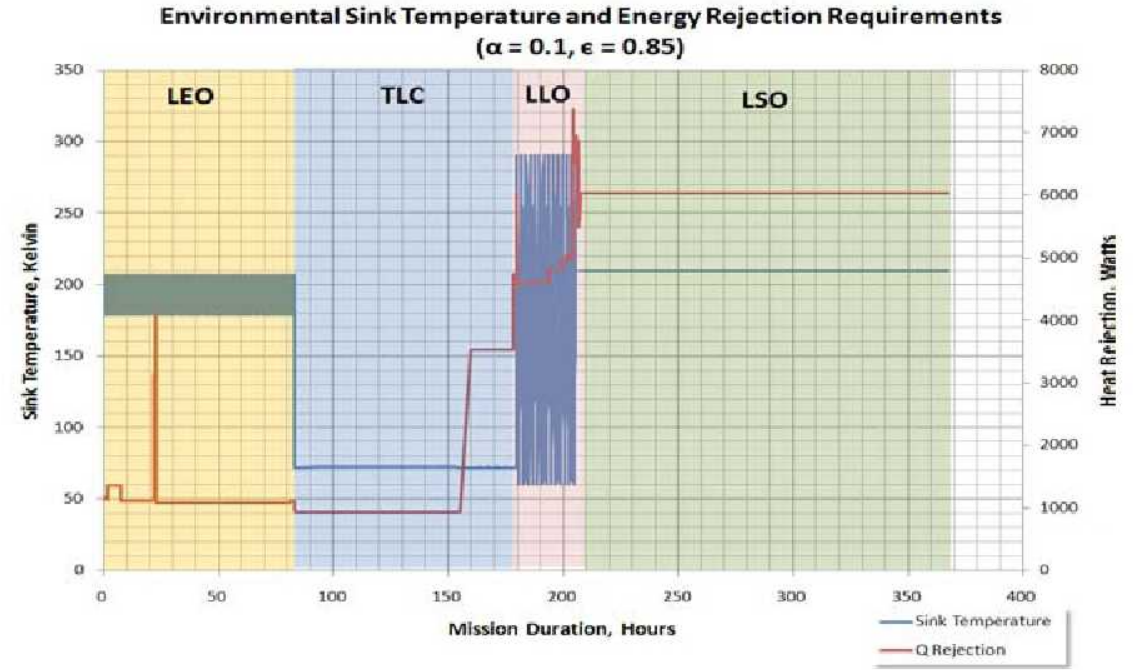

Figure 1. Altair Lunar Lander Environmental Sink Temperature and Energy Rejection Requirements for Various Mission Phases

susceptible to freezing at the lower heat rejection requirements and cooler sink temperatures. The problem of fluid freezing can be exacerbated by the need to return a fixed temperature to the cabin during every point of the mission.

Traditionally radiator temperatures are managed by controlling the spacecraft attitude, varying pumped-fluid flow rates, or varying the effective surface area by the use of thermal technologies such as louvers or variableconductance heat pipes, etc.). Often extra power must be supplied to radiators by thermostat-controlled heaters to survive the worst combinations of cold environments and low heat rejection loads. Pumps, louvers, heatpipes, and heaters (and their associated power systems) add mass to the radiator systems. In theory, much of this additional mass could be eliminated by actively changing the radiator's optical surface properties (emissivity and absorptivity), but until recently this was not practical. A simple relationship of this theory can be seen in using Equation 1 . While having a prescribed sink temperature $\left(\mathrm{T}_{\infty}\right)$ for different mission scenarios, a fixed radiator area $(\mathrm{A})$, and surface temperature $\left(\mathrm{T}_{\mathrm{s}}\right)$, changing the emissivity allows the user to vary the amount of heat rejection therefore preventing the fluid from freezing. A class of active surfaces known as variable emissivity electrochromic devices now makes this possible.

$$
Q=\varepsilon \sigma A\left(T_{\text {Sunfaces }}^{4}-T_{\text {Sink }}^{4}\right)
$$

A portion of this report outlines of two electrochromic radiator coupons that were designed and assembled to test the performance of variable emittance electrochromic devices provided by the Ashwin-Ushas Corporation. Another portion of this paper details the work performed on assessing the operation procedures of electrochromics as well as their capabilities during tests in a thermal vacuum chamber. Furthermore, analysis was performed to assess the potential of using electrochromics on full scale Altair radiators either alone or coupled with regenerative heat exchangers or bypass loop configurations,.

\section{Electrochromic Technology Assessment}

Functionally, variable emissivity electrochromic devices make use of an applied voltage to change the transmissivity of a highly emissive thin film. Switching states makes the layer transmissive, exposing a low emissivity surface underneath, giving the device a low emissivity. Figure 2 shows how the electrochromics switch 
between the high and low emissivity state. While Figure 2 shows visible switching, this visible change is also associated with a corresponding change in the IR spectrum in which the radiator emits energy.

Figure 3 below represents an electrochromic device on a thermally controlled surface. The device consists of two electrically active layers sandwiching an electrolyte.

The electrochromic device consists of a sandwich of two nearly identical electrodes, each having a conducting polymer film electro-deposited on a gold microporous membrane. The conducting polymer surface facing the space environment is the active electrochromic. The
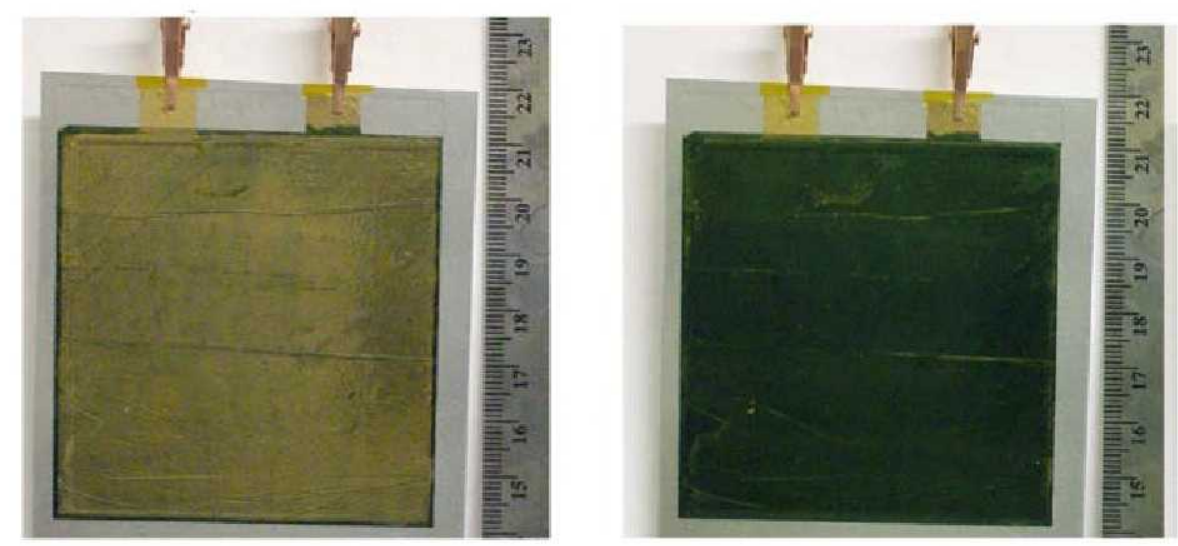

Figure 2. Electrochromics Showing Active Switching Area from Gold to Black electrolyte is contained within the mirco-pores of the membranes. By applying a small voltage $( \pm \sim 1$ V) through the electrodes, ions move through the electrolyte from one layer to the other. The addition and removal of ions causes a change in the emissivity of the electrochromic layer. For instance, the application of about positive 1 volt causes the layer to change its optical properties to an absorptive state. On the other hand, the application of negative voltage causes the optical properties to change to a transparent state allowing only the IR reflective layer to be seen. In all, the only two thermally active layers within the device

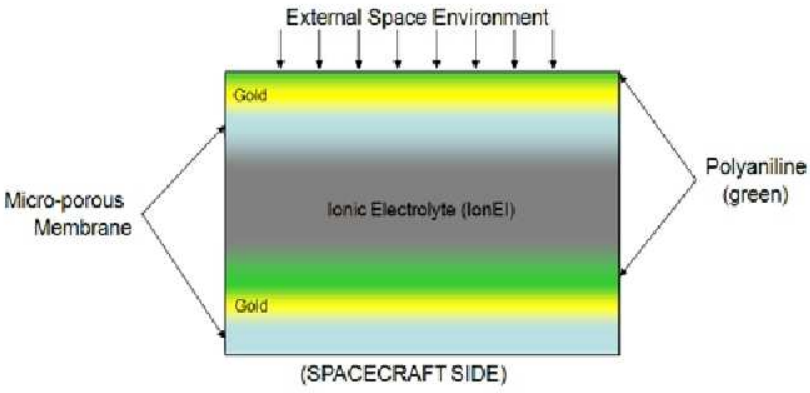

Figure 3. Electrochromic Device Illustration are the electrochromic layer and the IR reflective electrode.

The current state of the art in electrochromic technology includes products developed by Ashwin-Ushas Corporation and Eclipse Energy Systems. Other institutions and companies are performing research in this advancing field, but none market electrochromics for space applications. Of the two companies Ashwin was the only one that could provide coupons for the purposes of testing.

\section{Ashwin - Ushas Electrochromic Coupon Level Thermal Vacuum Testing}

This section will encompass the effort in designing and testing electrochromic test coupons. The effort helped in understanding electrochromic manufacturability and application process, capabilities in a relative environment, as well as the operational procedure of controlling electrochromics.

\section{A. Test Coupon}

In order to evaluate the performance of Ashwin-Ushas electrochromic devices, two coupons were assembled and tested with designations of coupon $\mathrm{A}$ and coupon $\mathrm{B}$. Coupons A and B each contain four electrochromic pixels similar to the one shown in Figure 4.

A representational cross section view of coupons A and B is shown in Figure 5. The coupons were fabricated using a 4.5 " x 4.5 " $\mathrm{x} 1 / 16$ " polished stainless steel plate as the

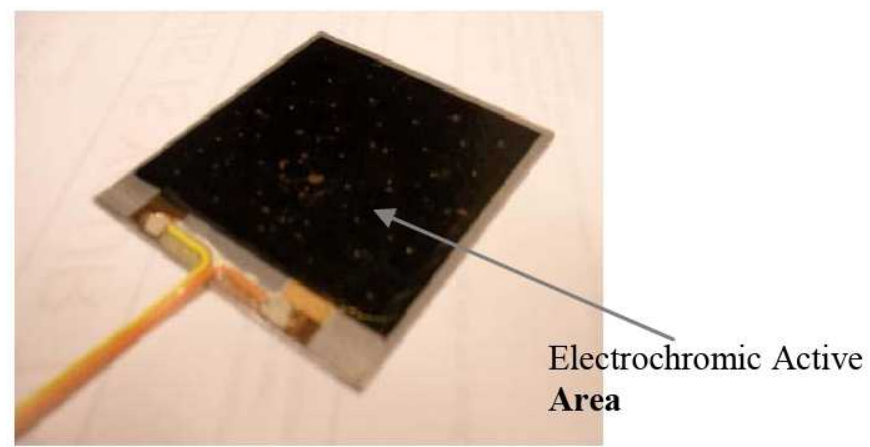

Figure 4. View an electrochromic device showing the active switching area in black. 
simulated radiator surface. A polished surface was specified to reduce heat loss from exposed surface area. The material choice and thickness was specified to allow good heat spreading while allowing for sensing of a failure in and single electrochromic device via thermal gradients. An array of nine thermocouples was

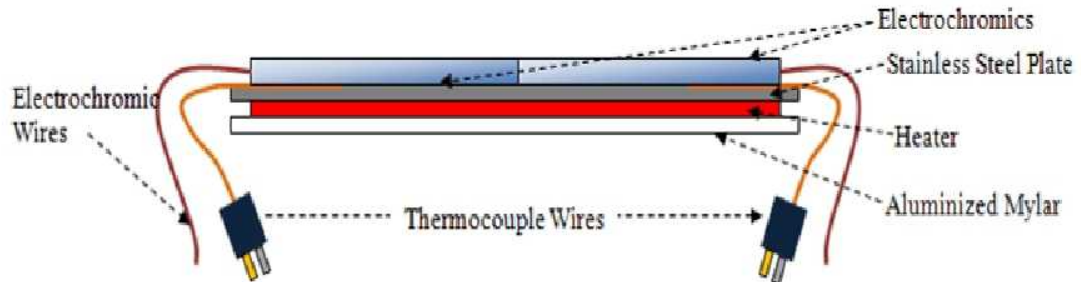

Figure 5. Side View of Electrochromic Test Coupons embedded to the back of the plate to obtain an average surface temperature of the coupon. Furthermore, these thermocouples were used to monitor whether an electrochromic pixel had failed to an emissivity state different from the other pixels by evaluating the gradient in the surface temperature. The thermocouples were embedded in order to allow for good thermal contact of the Kapton heater, which is applied behind the approximately 4.0 " x 4.0 " footprint of the electrochromic devices. The heater is covered by a layer of Aluminum tape to provide an additional thermal path in the event of de-lamination of the heater from the plate under vacuum conditions. A characterization test was ran to see if a 25 layer MLI blanket could be used to as a radiative insulator. Unfortunately an effective emissivity of 0.12 was calculated for the MLI, significantly lower then the predicted 0.01 to 0.05 effective emissivity expected. This high emissivity was believed to be due to the relatively small size of the blanket as well as the gap formed by attachment standoffs on the coupon for the MLI blanket. For this reason, the entire back side was covered by a layer of low emissivity Aluminized Mylar to reduce heat losses from the exposed back side.

The four electrochromic pixels were attached to the front side of the coupon using pressure sensitive adhesive that was pre-applied by Ashwin. The pixels we coated with an Alpha Z coating to reduce the solar absorptivity of the electrochromics. While the coupons were not tested with solar inputs, this layer is standard in the production of the devices. Beneath the Alpha Z coating is the active area of the electrochromics. Unfortunately, this coating is not the same size as the active area. Due to the variation in size between the active area and the electrochromic, an effective surface emissivity needed to be calculated for the entire electrochromic. Nonetheless, this understand helped

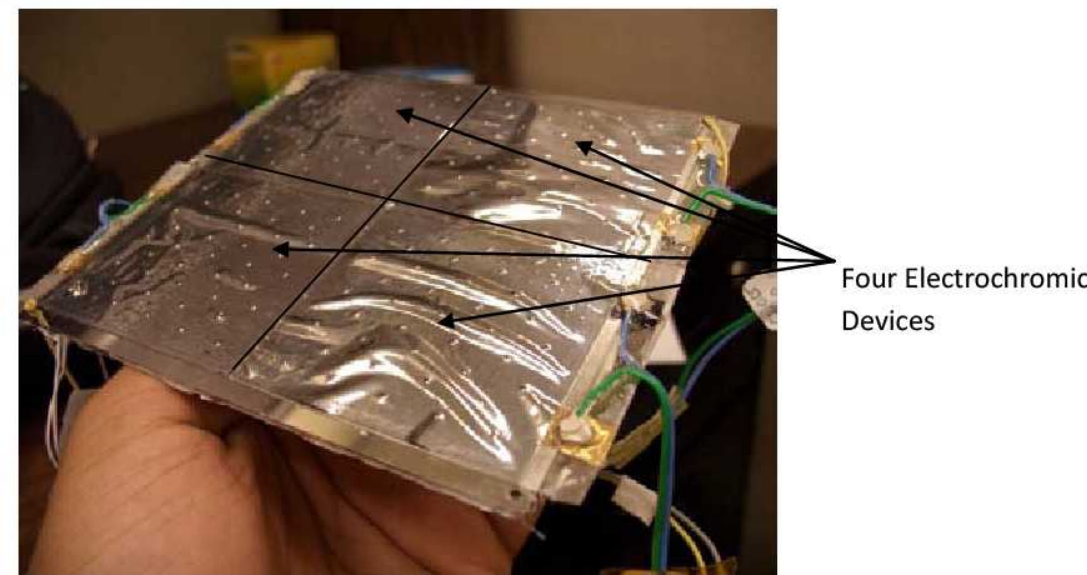

Figure 6 Assembled Electrochromic Coupon in performing an evaluation of the technology and future goals. An example of the active area is the black surface in the picture at the top in Figure 4. A final assembly of the coupon can be seen in Figure 6, where the active area is located under the shinny lower solar absorptance coating.

\section{B. Test Setup and Test Matrix}

The test setup included 10 power supplies to power the various electronic items on the test coupon. Two of the power supplies were used to power each of the heaters on each coupon individually. The other eight power supplies were used to power the each electrochromic on the two test coupons. Nine thermocouples were used on each coupon to monitor the surface temperature of the coupon. The two test coupons were suspended in the chamber using Kevlar string for its low thermal conductivity and ability to with stand the cold temperatures. A representation of the electrical layout and test buildup can be seen in Figures 7 and 8 respectively. 


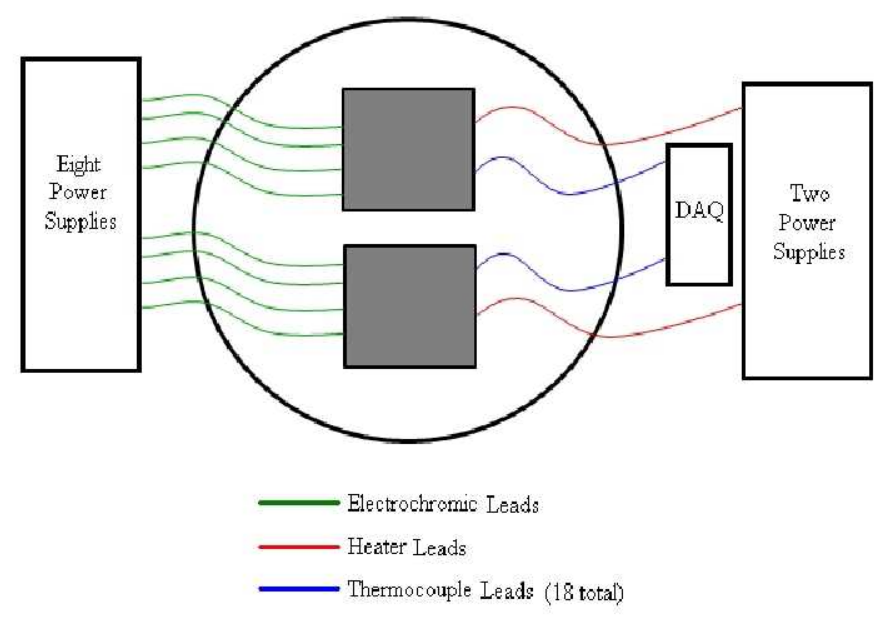

Figure 7. Simplified Electrical Layout

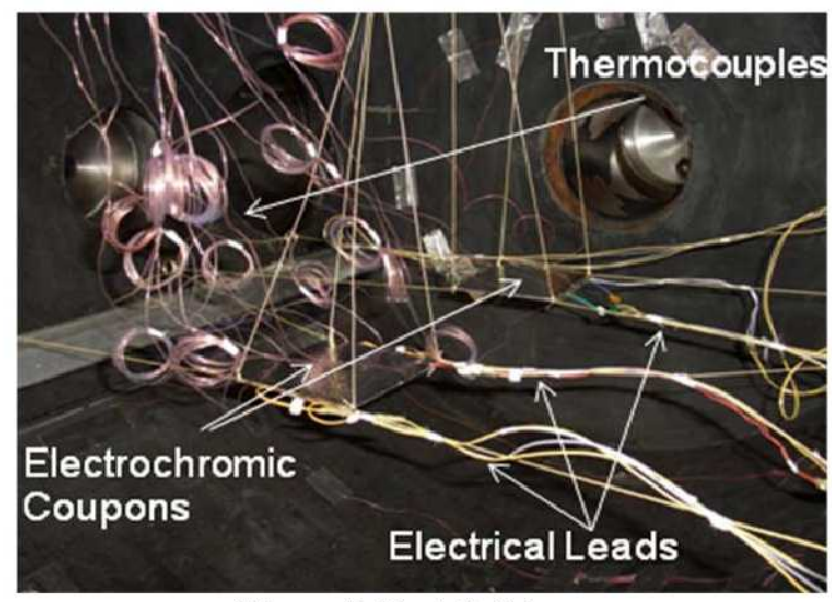

Figure 8. Test Buildup
Two components of the test setup were critical for gathering test data.

1.) DC Power Supplies - two power supplies were used to control the heaters. In addition, eight power supplies were used to vary the voltage of the electrochromics between -1.0 and 0.3 Volts. These voltage settings correspond to the device's low and high emissivity states respectively.

2.) DAQ System - Records the nine thermocouples located on each test article. For use, the values recorded by the thermocouples were averaged and used as the single plate temperature in all calculations.

Over the course of the test program, eight test sets were run. Power input to the coupon heaters and the voltage input to the electrochromic pixels were varied during the tests to hold the coupon at target temperatures between $-20^{\circ} \mathrm{C}$ and $50^{\circ} \mathrm{C}$. This range was deemed applicable for use on an Altair radiator. For each gathered test set, the power was held at a steady value until the temperature stabilized and was held constant for at least an hour to assure achievement of steady state. Heater power, average thermocouple temperatures, and electrochromic voltage setting was recorded every 10 minutes.

A simple energy balance was used to assess the emissivity of the electrochromics for a given voltage setting and resulting steady state plate temperature. A derivation of the equation used to determine the effective emissivity of the electrochromic active area can be seen below in Equation 2.

To better quantify the performance of the electrochromics, various sources of energy losses were taken into account in the calculations. Losses from the back side of the coupon, exposed stainless steel surface, inactive electrochromic area, electrical tabs from the electrochromics, and electrical wires were calculated. Using the emissivity, surface area, and average surface temperature of each surface where energy was lost, Equation 1 was used to calculate the individual losses and then summed together as an overall energy loss from the coupon $\left(\mathrm{Q}_{\text {losses }}\right)$. Losses from the electrical/thermocouple wires and support strings were considered separately in a modeling and energy balancing exercise. A table comparing applied energy and calculated energy losses for a corresponding test point can be seen in Table 1. Larger than expected heat leaks were experienced during testing because of this greater uncertainty was associated to the calculated emissivity of the electrochromics. 


\section{Test Results}

Table 1 Energy Input and Losses for Each Coupon at Each Test Point

A delta emissivity and absolute emissivity were calculated for each coupon at the various surface

$$
\begin{gathered}
Q_{\text {in }}=Q_{\text {out }} \\
V \cdot I-Q_{\text {losses }}=\varepsilon \cdot A \cdot \sigma \cdot\left(T_{\text {surface }}^{4}-T_{\text {sin } k}^{4}\right) \\
\varepsilon=\frac{V \cdot I-Q_{\text {losses }}}{A \cdot \sigma \cdot\left(T_{\text {surface }}^{4}-T_{\sin k}^{4}\right)}
\end{gathered}
$$

temperatures. The four individual electrochromics on each coupon were treated as one composite electrochromic. Nonetheless, the determination of the

\begin{tabular}{|c|c|c|c|c|c|}
\hline \multirow{2}{*}{ Test Points } & \multicolumn{2}{c|}{ Coupon A } & \multicolumn{2}{c|}{ Coupon B } \\
\cline { 2 - 6 } \multicolumn{2}{|c|}{} & $\begin{array}{c}Q_{\text {in }} \\
(W)\end{array}$ & $\begin{array}{c}Q_{\text {losses }} \\
(W)\end{array}$ & $\begin{array}{c}Q_{\text {in }} \\
(W)\end{array}$ & $\begin{array}{c}Q_{\text {losses }} \\
(W)\end{array}$ \\
\hline \multirow{4}{*}{$\begin{array}{c}\text { High } \\
E\end{array}$} & -20 & 2.13 & 1.09 & 2.23 & 1.12 \\
\cline { 2 - 6 } & -5 & 2.76 & 1.35 & 2.75 & 1.36 \\
\cline { 2 - 6 } State & 10 & 3.55 & 1.70 & 3.79 & 1.81 \\
\cline { 2 - 6 } & 35 & 4.97 & 2.34 & 5.03 & 2.42 \\
\cline { 2 - 6 } & 50 & 5.85 & 2.82 & 6.22 & 3.07 \\
\hline \multirow{4}{*}{$\begin{array}{c}\text { Low } \\
\text { E }\end{array}$} & -20 & 1.54 & 1.08 & 1.65 & 1.10 \\
\cline { 2 - 6 } State & -5 & 2.01 & 1.38 & 2.21 & 1.44 \\
\cline { 2 - 6 } & 10 & 2.51 & 1.70 & 2.75 & 1.77 \\
\cline { 2 - 6 } & 35 & 3.64 & 2.37 & 3.87 & 2.47 \\
\cline { 2 - 6 } & 50 & 4.40 & 2.86 & 4.60 & 2.96 \\
\hline
\end{tabular}
delta emissivity was found to be very simple. This is because the delta emissivity calculation only requires the change in power required to hold the device at a set temperature. This relationship can be seen in Equation 3 .

$$
\Delta \varepsilon=\varepsilon_{\text {high }}-\varepsilon_{\text {low }}=\frac{Q_{\text {high }}-Q_{\text {Low }}}{A_{A} \cdot \sigma \cdot\left(T_{\text {surface }}^{4}-T_{\sin k}^{4}\right)}
$$

Initial calculations using an active area measurement of $0.013 \mathrm{~m}^{2}\left(20.25 \mathrm{in}^{2}\right)$, which is the entire front surface area of the test coupon, resulted in a delta emissivity of $\mathrm{e}=$ 0.21 and 0.19 for coupon A and B respectively. This is indicative of the composite performance of the coupon as a radiator. If only the area covered by the alpha $\mathrm{Z}$ coating of the electrochromic devices (the perforated, wavy, silver material in Figure 6) is considered, the values raise to $\Delta \mathrm{e}$ $=0.23$ and 0.21 for coupons $\mathrm{A}$ and $\mathrm{B}$ respectively. This performance is far short of the expected values of $\mathrm{e}=0.34$ and 0.32 reported by the manufacturer. Upon discussing the results with Ashwin, it was found that a significant edge portion of the device does not take part in the emissivity switch, therefore resulting in a even smaller switching active area. The devices are constructed from a series of progressively smaller layers, resulting in the smallest area being the electrochromic switching active area. Using this smaller surface area, the average device delta emissivity over all temperatures was calculated to ber $\mathrm{e}=0.29$ and 0.26. This is still less than the reported values by Ashwin by about $14 \%$ for coupon $\mathrm{A}$ and $19 \%$ for coupon B. Furthermore, the measured delta emissivity was highest near room temperature for both coupons, which can

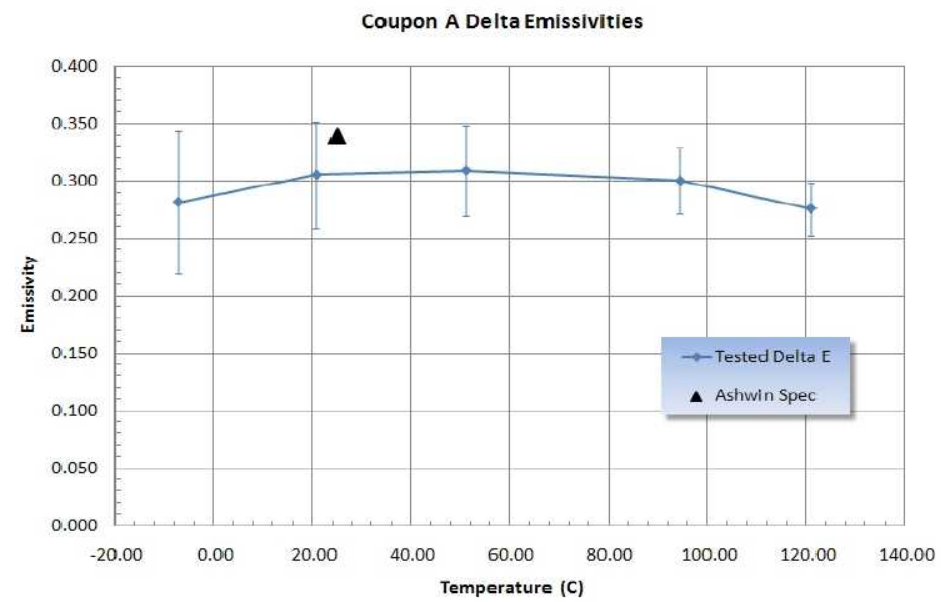

Figure 9. Measured and Vendor Specified Delta Emissivity for Electrochromic Coupon A

be seen in Figure 9 and Figure 10 . At about $20^{\circ} \mathrm{C}$ the difference between test and spec data reduces to approximately $10 \%$ and $15 \%$ for the two coupons. 


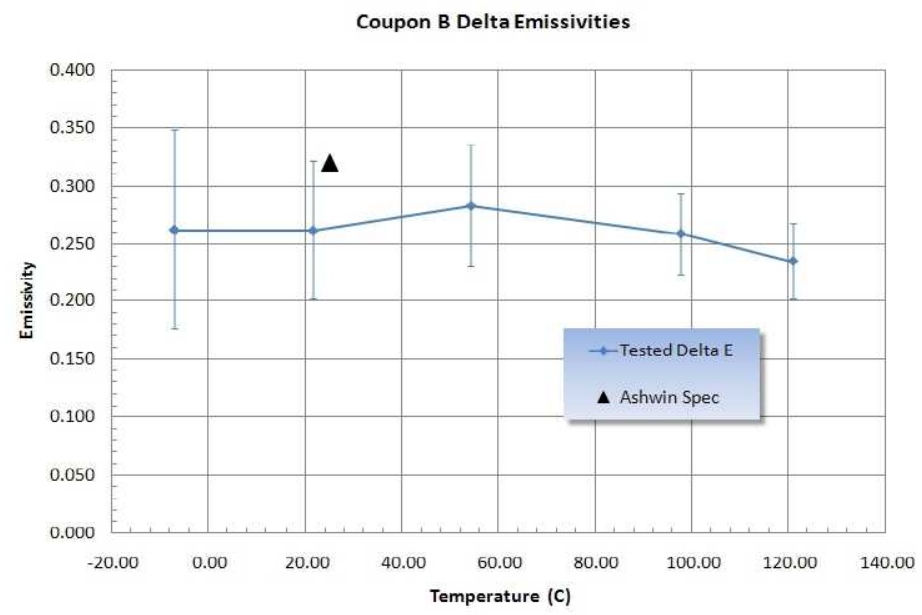

Figure 10 Measured and Vendor Specified Delta Emissivity for Electrochromic Coupon B
Unlike the delta emissivity calculations, when calculating the absolute emissivity, the various heat losses throughout the test article needed to be taken into account. This is because the heat losses where about the same for the low power setting as well as high power settings for the set coupon temperature. Unfortunately, this meant many more unknowns needed to be investigated, making the calculation cantankerous. Nonetheless, using the summation of losses found for each individual surface and inputted energy as described in Table 3, Equation 2 was used to calculate the absolute emissivity of the electrochromics. One should note that higher than expected uncertainties were calculated for the emissivities due to the large amounts of heat loss in test. Specifically, the uncertainty value for calculated emissivity spans between $25 \%$ to as much as $34 \%$ of the calculated value. The result of each coupon's absolute emissivity can be seen in Figures 11 and 12. The values are specified for the range of temperatures the coupons were tested to. Also, a vendor specified averaged high and low emissivity was plotted as a reference. The vendor data was taken using an emissometer at room temperature.

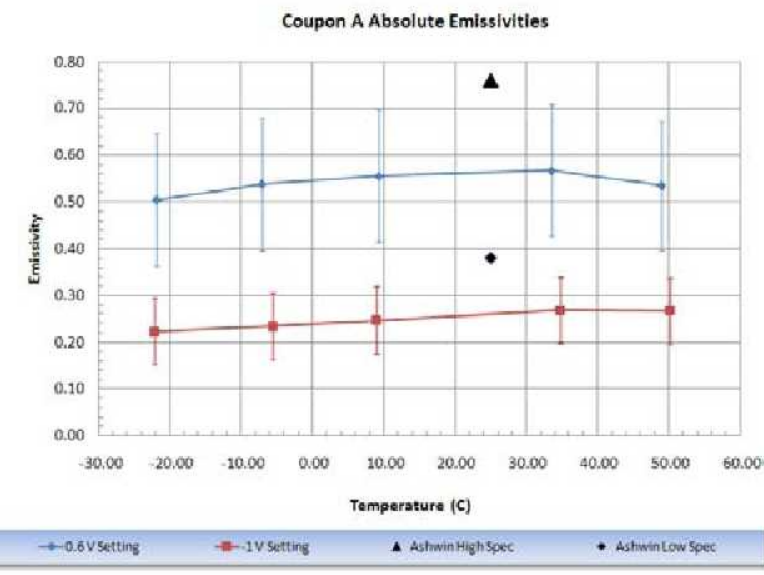

Figure 11 Coupon A Calculated and Vendor Specified Electrochromic Absolute Emissivity

The high expected emissivity state was never reached on either coupon. The calculated values for emissivity near room temperature were approximately 0.17 lower than the specified values for both coupons. Furthermore, the calculated tests results were 0.13 and 0.10 lower than Ashwin's predications when the pixels were set to the low emissivity state respectively. While these are relatively large differences, they do fall within the range on uncertainties calculated for these tests as seen in Figure 12. Figure

Table 2 Summary of Coupon A and Coupon B Electrochromic Performance

\begin{tabular}{|l|c|c|c|c|}
\hline & \multicolumn{2}{|c|}{ Coupon A } & \multicolumn{2}{c|}{ Coupon B } \\
\hline & $\begin{array}{c}\text { Test } \\
\text { results }\end{array}$ & $\begin{array}{c}\text { Vendor } \\
\text { specification }\end{array}$ & $\begin{array}{c}\text { Test } \\
\text { results }\end{array}$ & $\begin{array}{c}\text { Vendor } \\
\text { specification }\end{array}$ \\
\hline$\varepsilon$ low & 0.25 & 0.40 & 0.27 & 0.39 \\
\hline$\varepsilon$ high & 0.54 & 0.74 & 0.54 & 0.71 \\
\hline$\varepsilon$ delta & 0.29 & 0.34 & 0.26 & 0.32 \\
\hline$\varepsilon$ high/ $\varepsilon$ low & 2.16 & 1.85 & 2.00 & 1.82 \\
\hline
\end{tabular}
11 on the other hand shows the vendor data close to falling within the uncertainty bands of the test. Nonetheless, a summary of the calculated delta, absolute, and vendor specified emissivities for the two coupons can be seen in Table 2. The data in the table represents the highest and lowest absolute and delta emissivity the coupons were tested to during the entire test time. In all, the emissivity turndown ratio experienced during test was about 2 to 1 , relatively close to the vendor specified turndown ratio. 
During test, another characteristic of the electrochromics was found to be that they experienced a slow switch time at colder temperatures. Test Set 1 was initially run first at a high emissivity setting for a range of temperatures. Once the set was complete, Test Set 2 was run by first allowing the coupon temperature to go down to $-20^{\circ} \mathrm{C}$

Table 3 Description of Each Test Set Tested

\begin{tabular}{|lll|}
\hline Test Set 1 & - & Pixels set to $0.3 \mathrm{~V}$ and tested from $-20 \mathrm{C}$ to $50 \mathrm{C}$ \\
\hline Test Set 2 & - & Pixels set to $-1 \mathrm{~V}$ and tested from $-20 \mathrm{C}$ to $50 \mathrm{C}$ \\
\hline Test Set 3 & - & Pixels left at $-1 \mathrm{~V}$ and tested from $-20 \mathrm{C}$ to $50 \mathrm{C}$ (Repeatability) \\
\hline Test Set 4 & - & Pixels unpowered for an hour and then $-1 \mathrm{~V}$ was reapplied, kept at $50 \mathrm{C}$ \\
\hline Test Set 5 & - & Pixels set to $0.3 \mathrm{Vs}$ and tested from $-20 \mathrm{C}$ to $50 \mathrm{C}$ (Repeatability) \\
\hline Test Set 6 & - & Pixels unplugged and then $0.3 \mathrm{~V}$ was reapplied, kept at $50 \mathrm{C}$ \\
\hline Test Set 7 & - & Three pixels at a time set to $0.3 \mathrm{~V}$ and one pixel at $-1 \mathrm{~V}$, kept at $50 \mathrm{C}$, \\
\hline Test Set 8 & - & All four pixels cycled from 0.3 to -1 Volts, kept at $50 \mathrm{C}$ \\
\hline
\end{tabular}

and then switching to a lower state emissivity. Table 3 summarizes each test set ran with a brief description of what was performed during the set. Furthermore, Figure 13 shows how the coupon did not change to the lower emissivity state until it was warm enough to do so. This slow response time was also seen when going from a low emissivity state to a high emissivity state in the same fashion, as seen in Figure 14. Furthermore, the coupon was never able to achieve the highest emissivity tested during Test Set 1 at any other point during the test duration. This indicated a degradation in performance of the electrochromics as the test went along. A possible cause of this degradation could be due to the cold temperatures the electrochromics were subjected to, as agreed on by the vendor as a possible cause.

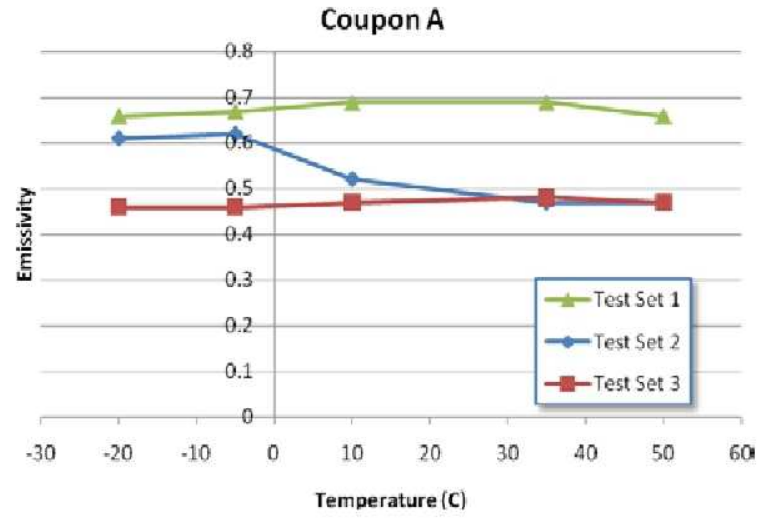

Figure 13 Electrochromic Coupon A High to Low Emissivity Switching Response

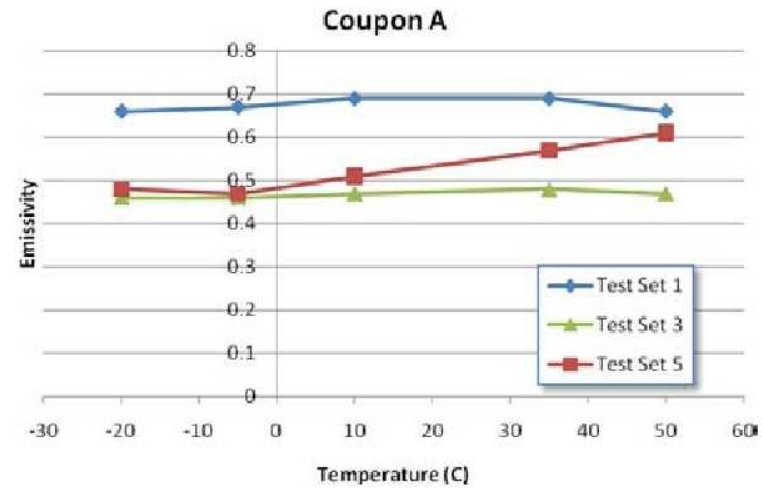

Figure 14 Electrochromic Coupon A Low to High Emissivity Switching Response

\section{Coupon Level Future Analysis}

Another coupon level test will be run and reported on that has a goal of reducing the error at minimum by $50 \%$. This new coupon level test will incorporate a new coupon design, aimed at reduceing the error associated to the coupon design such as heat leak. Furthermore, the coupon will have a new set of electrochromics with an increased emissivity turndown ratio as well as a better response to cold temperatures. The reduction in uncertainty is made possible by the addition of a guard heater plate and agreements with Ashwin to have $100 \%$ effective area, pixel size tolerances of $+/-1 \mathrm{~mm}$, and the electrical tabs made at a $90^{\circ}$ to the test article. The guard heater plate minimizes heat leak from the back of the test plate and greatly reduces heat leak from the wires. Ashwin's agreement removes other sources of error by insuring a known total area and a maximized active area ratio. Ashwin also believes that the other problems noted in the last test such as degradation of performance and trouble switching at cold temperatures has been resolved.

Ashwin is currently partaking in an effort to improve their emissive turn down ratio of at least 3 to 1 with a goal of achieving a higher value if possible. Moreover, they are looking into changing the electrolytes used to develop the electrochromics to increase emissivity switching time at lower temperatures. 


\section{Altair Lunar Lander Full Scale Electrochromic Radiator Thermal Math Modeling}

The full scale modeling section shows the optimization process used to select a radiator configuration that meets the Altair requirements. The requirements of the Altair Lunar Lander Thermal Control System (TCS) include operation in a large range of thermal environments along with varying power and heat rejection levels. While meeting the Altair's requirements the optimization will primarily focus on mass and emissivity ratio. The emissivity ratio is the ratio for the high emissivity state the electrochromics would be while experiencing the highest heat loads and the low emissivity the state electrochromics would be in during the lowest heat loads. The emissivity ratio needed to meet the Altair requirements compared to the projections of what this technology is capable of will show if this technology is worth pursuing. The mass will show how it compares to other high turndown technologies. To show the optimization process this section will first define the requirements and environment for the Altair mission. Next the methods and process used to evaluate the performance of various radiator configurations will be discussed. Finally the data for panel and emissivity ratio optimizations will be presented.

\section{A. Background and Requirements}

The radiators will be designed around the Altair Lunar Lander environmental conditions. The requirements for this effort are also show in Table 4.

There is also a goal of a foot print of $2.0 \mathrm{~m} \times 3.7 \mathrm{~m}$ for each panel meaning a total maximum area of $29.6 \mathrm{~m} 2$. Another goal is that the radiator system only contains four identical panels.

Environments for these cases are representative of lunar surface operations for the hot case and translunar coast for the cold case. The following fields must be completed:

1) A hot case where the system rejects $6040 \mathrm{~W}$ of internal heat. An averaged absorbed heat load of $340 \mathrm{~W} / \mathrm{m} 2 \cdot \alpha$ of solar gain and $70 \mathrm{~W} / \mathrm{m} 2 \cdot \varepsilon$ of IR gain is assumed where $\varepsilon$ is the surface emissivity and $\alpha$ is the surface solar Table 4 Thermal Math Modeling Requirements

\begin{tabular}{|l|l|}
\hline \multicolumn{1}{|c|}{ Requirement } & \multicolumn{1}{c|}{ Justification } \\
\hline $\begin{array}{l}\text { System can reject } 6040 \mathrm{~W} \text { in } \\
\text { steady state operation in a LSO }\end{array}$ & Maximum net heat rejection case \\
\hline $\begin{array}{l}\text { System can reject } 936 \mathrm{~W} \text { in } \\
\text { steady state operation in a }\end{array}$ & Minimum net heat rejection case \\
\hline $\begin{array}{l}\text { System will have a constant } \\
\text { total flow rate. }\end{array}$ & $\begin{array}{l}\text { Eliminates need for variable speed } \\
\text { pump }\end{array}$ \\
\hline $\begin{array}{l}\text { System Return temperature to } \\
\text { cabin of } 283 \mathrm{~K}\end{array}$ & Altair based requirement \\
\hline $\begin{array}{l}\text { Maximum system inlet } \\
\text { temperature of 313 K }\end{array}$ & Altair based requirement \\
\hline $\begin{array}{l}\text { Return temperature margin of } \\
+/-3 \mathrm{~K}\end{array}$ & $\begin{array}{l}\text { Required for evaluation of full flow } \\
\text { pixilation and control scheme }\end{array}$ \\
\hline $\begin{array}{l}\text { Maximum radiator pressure } \\
\text { drop of } 10 \text { psid }\end{array}$ & Orion heritage value \\
\hline $\begin{array}{l}\text { Working fluid is PGW 50/50 } \\
\text { by weight. Properties give in }\end{array}$ & Design commonality and safety \\
\hline $\begin{array}{l}\text { System is able to increase from } \\
\text { minimum heat rejection at a }\end{array}$ & $\begin{array}{l}\text { System responsiveness to } \\
\text { environmental change. }\end{array}$ \\
\hline
\end{tabular}
absorptivity. The emissivity is defined as a variable since the emissivity of the device is a function of predicted high and low values for this technology.

2) A cold case where the system rejects $936 \mathrm{~W}$ of internal heat with an absorbed solar load heat load of $0.012 \mathrm{~W} / \mathrm{m} 2 \cdot \alpha$ and an absorbed IR load of $1.558 \mathrm{~W} / \mathrm{m} 2 \cdot \varepsilon$.

The alpha value is predicted as 0.25 throughout the analysis based on projections of possible Ashwin alpha reducing designs, and two high emissivity values are analyzed, 0.9 and 0.7 , which are also prospective in nature. These values represent an upper limit similar to that of white paint, and a lower value which is thought to be achievable with electrochromic designs. These heat loads and surface optical properties can be used to produce equivalent sink temperatures via equation 4 .

The resulting equivalent sink temperatures for the bounding hot and cold cases that are used in the analysis are shown in Table 5.

$$
T_{\sin k}=\left(\frac{\left(\frac{\alpha}{\varepsilon}\right) q_{\text {solar }}+q_{\text {IR }}}{\sigma}\right)^{(1 / 4)}
$$


Table 5 Equivalent Sink Temperatures

The sink temperatures shown in Error! Reference source not found. are forth order averaged values for the four radiator panels. Under these requirements and using the foot print requirement the turn down ratio is 10.65 as

\begin{tabular}{|l|c|c|}
\hline $\boldsymbol{\alpha}=\mathbf{0 . 2 5}$ & $\boldsymbol{\varepsilon}=\mathbf{0 . 9}$ & $\boldsymbol{\varepsilon}=\mathbf{0 . 7}$ \\
\hline Cold K & 72 & 72 \\
\hline Hot K & 232 & 241 \\
\hline
\end{tabular}
obtained by equation 5 .

$$
\frac{q_{1}+q_{\text {solar } 1} \cdot A+q_{I R 1} \cdot A}{q_{2}+q_{\text {solar } 2} \cdot A+q_{I R 2} \cdot A}=\frac{6040 \mathrm{~W}+0.25 \cdot 340 \frac{\mathrm{W}}{\mathrm{m}^{2}} \cdot 29.6 \mathrm{~m}^{2}+0.9 \cdot 70 \frac{\mathrm{W}}{\mathrm{m}^{2}} \cdot 29.6 \mathrm{~m}^{2}}{936 \mathrm{~W}+0.25 \cdot 0.012 \frac{\mathrm{W}}{\mathrm{m}^{2}} \cdot 29.6 \mathrm{~m}^{2}+0.9 \cdot 1.558 \frac{\mathrm{W}}{\mathrm{m}^{2}} \cdot 29.6 \mathrm{~m}^{2}}=10.65
$$

B. Methods and Analysis

Three flow configurations through the radiators are to be considered:

1) Full flow at the hot case optimizing the panels mass and evaluating the overall turndown need..

2) Bypass flow at the cold case where the average temperature to the radiator is reduced by shunting a fraction of the flow around the radiator. The mixed return to the cabin is the same as in full flow. Emissivity ratio optimization to get the lowest emissivity ratio possible.

3) Bypass flow plus the use of a regenerative heat exchanger (RHX) at the cold case where the non-bypassed flow is pre-cooled by RHX with the outlet flow from the radiators. Emissivity ratio optimization.

Several radiator designs can be explored to meet the hot case requirements. Variable parameters include panel type (single solid sheet or aluminum honeycomb panel), facesheet thickness, number of tubes and the spacing of the tubes, and total area of the panel. All of these factors can be adjusted and are dependent on each other so many permutations can be made which all satisfy the basic requirements.

To perform all the needed cases an Excel tool was used that had gone through a privies validation effort. This tool was used in lieu of Thermal Desktop because it provides a fast and accurate way to run many iterations. Further efforts validated the Excel model by developing Thermal Desktop models of specific cases and ensuring that the results match.

This Excel tool takes in the basic parameters of a fin tube radiator then traces the heat transfer from the fluid to the fluid tube and from the fin root temperature (which is the fluid tube temperature) out to the rest of the fin. In the calculations of the heat transfer from fluid to tube fully developed laminar flow in a circular tube is the assumed, ref. 1 has calculations use to find heat transfer and pressure drop from these assumptions. To find the temperature distribution in the radiator and from there find the fin efficacy for a given section a few assumptions were made. The first is that the fin root temperature is equal to the tube temperature; the next is that the temperature is constant along the length of the fin being evaluated (each radiator is broken down into 100 sections). Then equation 6 is used which is from Ref 2 .

In this equation $\mathrm{k}$ stands for the conductivity of the facesheet, $t$ is the thickness of the facesheet, $T$ is the

$$
-k t \frac{d^{2} T}{d x^{2}}+2 \varepsilon \sigma T^{4}=q_{a b s, t}+q_{a b s, b}
$$
temperature for a give point on the facesheet, $\mathrm{x}$ is a position along the width of the panel, qabs, $t$ and qabs, $b$ are the fluxes absorbed on the top and bottom sides respectively. Figure 15 shows a diagram of the radiator. Equation 6 is altered with the assumption that the radiator is only radiating out of one side and that the heat from the surroundings can be accounted for in the sink temperature and becomes equation 7 .

$$
\frac{d^{2} T}{d x^{2}}-\frac{\varepsilon}{k t} \sigma\left(T^{4}-T_{\infty}^{4}\right)=0
$$

Using this equation and

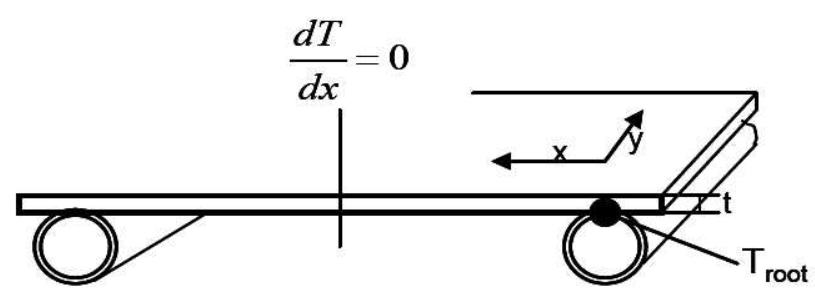

Figure 15. Diagram of Fin-Tube Radiator the equation is numerically solved to yield the temperature distribution. Once the temperature distribution is found, the fin efficiency can be obtained by dividing the heat rejection capability of the radiator with this distribution by what the radiator would reject if the entire panel was at the fin root temperature. Equation 8 shows the mathematical formulation of the fin efficiency. 
Several modifications, all validated, had to be made to the Excel model. First, a way to model an aluminum honeycomb panel as a solid was added. To get the basic parameters of an aluminum honeycomb panel needed for modeling, the parameters given in Table 6 were taken from a shuttle radiator

$$
\eta=\frac{\int\left(T^{4}-T_{\infty}^{4}\right) d A}{A\left(T_{\text {root }}^{4}-T_{\infty}^{4}\right)}
$$
design.

Table 6. Core Properties

\begin{tabular}{|l|r|}
\hline Material & $\mathrm{Al}$ 5056-H38 \\
\hline Thickness, $\mathrm{m}$ & 0.0127 \\
\hline Core Density, $\mathrm{kg} / \mathrm{m} 3$ & 50 \\
\hline Material Density, $\mathrm{kg} / \mathrm{m}^{3}$ & 2632 \\
\hline Heat Capacity, $\mathrm{kJ} / \mathrm{kg} /{ }^{\circ} \mathrm{C}$ & 0.92 \\
\hline Cell Side Length, $\mathrm{m}$ & 0.0048 \\
\hline
\end{tabular}

Using the properties from Table 6, the conductivity for the honeycomb core is $0.991 \mathrm{~W} / \mathrm{m} / \mathrm{K}$ laterally and $2.115 \mathrm{~W} / \mathrm{m} / \mathrm{K}$ normal to the panel. Modeling showed that the panel was isothermal in the normal direction but adjustments need to be made to account for the added conductivity in the lateral direction. Equation (9) shows the steps needed to get a multiplication factor that could be applied to the conductivity of a solid plate at the thickness of both facesheets added together.

$$
\begin{aligned}
& q=-k A \frac{d T}{d x}=-k t w \frac{d T}{d x} \\
& \frac{d T}{d x} w k_{k @ t} t_{\text {facesheet }} 2=k_{\text {core }} t_{\text {core }} w \frac{d T}{d x} \\
& k_{k @ t} t_{\text {facesheet }} 2=k_{\text {core }} t_{\text {core }} \\
& k_{k @ t}=0.9914 \frac{W}{m K} * 0.00127 m * \frac{1}{2} * \frac{1}{t_{\text {facesheet }}} \\
& k_{\text {total }}=k_{k @ t}+k_{\text {facesheet }} \\
& M_{k}=\frac{k_{\text {total }}}{k_{\text {facesheet }}}
\end{aligned}
$$

In Equation (9) $q$ is the heat load, $M_{k}$ is the conductivity multiplication factor, $k_{k @ t}$ is thermal conductivity of the core at the facesheet's thickness, $\mathrm{k}_{\text {facesheet }}$ is thermal conductivity of the facesheet, $\mathrm{t}_{\text {core }}$ is core thickness, $\mathrm{t}_{\text {facesheet }}$ is facesheet thickness, $\mathrm{w}$ is the width of the panel, $\mathrm{dT}$ is the change in temperature, $\mathrm{dx}$ is the lateral distance from one point in the panel to another. When modeling aluminum honeycomb in the Excel tool, the facesheet thicknesses are added together and the derived multiplication factor is applied to the material conductivity.

To optimize for emissivity ratio the use of a bypass loop was considered. A few simple operations where made inside the Radiator Heat Rejection Calculation Excel worksheets to test different radiator configurations with bypass flow. The flow rate to the radiator is lowered to simulate some flow going through the bypass and then equation (10) was solved to determine the mixed final temperature.

$$
-Q_{\text {total }}=\dot{m}_{\text {total }} c p\left(T_{\text {final }}-T_{\text {in }}\right)
$$

Where Qtotal is the total heat rejected by the radiators, $\dot{m}_{\text {total }}$ is the total flow going through the bypass and to the radiators, $\mathrm{cp}$ is the heat capacity of the fluid at the mixed temperature, Tfinal is the temperature going to the cabin, and Tin is the temperature of the fluid going into the bypass and the radiator. The heat rejection results found by the Excel with this equation were compared to the full scale Thermal Desktop model and found to match.

The final step taken to optimize the emissivity ratio was to analyze the use of a RHX. The RHX lowers the inlet temperature of the radiator by transferring heat from the fluid going to the radiator to the fluid coming from the radiator. The change in the inlet temperature helps turndown the radiator because if the average temperature of the radiator is lower, less energy is radiated away. In the assembly modeled, the flow not diverted through the bypass flows through the RHX before entry into the four radiator panels in series. The RHX was analyzed inside the 
Thermal Desktop model used for verification of the Excel tool. Previously written and verified code was used when modeling the RHX. The mathematical formulation used to simulate the RHX is presented in equation (11).

$$
\begin{aligned}
& d T_{\max }=\left(T_{\text {pump }}-T_{\text {out }}\right) R H X_{\text {eff }} \\
& T_{C S}=T_{\text {out }}+d T_{\max } \\
& q_{\text {trans }}=d T_{\max } \dot{m}_{\text {rad }} c p \\
& q_{\text {trans }}=\left(T_{\text {pump }}-T_{\text {in }}\right) \dot{m}_{\text {rad }} c p \\
& T_{\text {in }}=T_{\text {pump }}-d T_{\max }
\end{aligned}
$$

Equation (11) shows how the two key parameters are obtained, that of $\mathrm{T}_{\mathrm{cs}}$, the outlet of the RHX on the cold side where the fluid goes towards the cabin and Tin, the temperature of the fluid going to the radiator. $\mathrm{T}_{\text {pump }}$ is the temperature directly leaving the cabin, Tout is the radiator outlet temperature, $\mathrm{cp}$ is the heat capacity of the fluid,

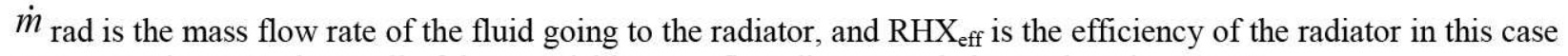
set to 0.8 . Figure 16 shows all of these variables on a flow diagram to help put them in context.

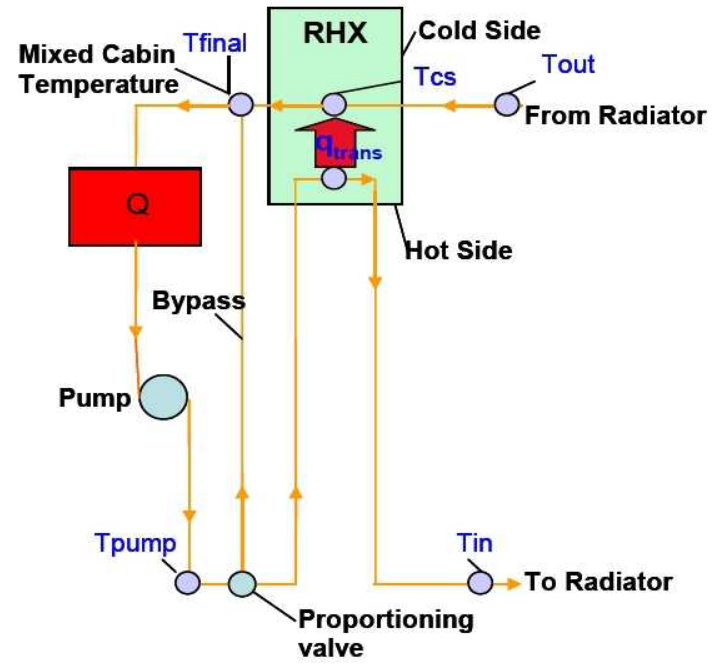

Figure 15. RHX Diagram

In Thermal Desktop, $\mathrm{q}_{\text {trans }}$ the heat used to change Tout to Tcs, , is removed from the fluid going to the radiator. This was done so that changes in $\dot{m}_{\text {rad }}$ and the difference between the two specific heats would be taken into account automatically and conservation of energy is preserved.

The mass shown in the results is based on a total of electrochromics, facesheet, the honeycomb core, facesheet tubes, and manifold masses. The tube mass includes the mass of the contained fluid. System level masses are not taken into account. Some examples of system level masses are the tubes that connect radiator panels and the RHX itself.

\section{Panel Optimization, Hot Case}

For the full flow hot case, several trades were considered in the process of determining an optimum radiator: optimizing the panel for mass savings, use of an aluminum honeycomb panel, 0.9 and 0.7 max emissivity, the suggested area requirement, and the tube spacing on a panel.

The results for either a 0.7 or 0.9 max emissivity show that a panel optimized for mass has a very thin facesheet. Thin facesheets suggest the use of an aluminum honeycomb panel for structural reasons. The results from the tube spacing analysis show mass efficient methods to fit inside the foot print goal. Table 7 lists some of the assumed parameters. 
Table 7. Set Parameters

\begin{tabular}{|l|r|}
\hline Electrochromics areal Density, $\mathrm{kg} / \mathrm{m} 2$ & 0.6 \\
\hline Manifold Inner Diameter, $\mathrm{m}$ & 0.0115 \\
\hline Manifold Tube Thickness, $\mathrm{mm}$ & 0.508 \\
\hline Tube Thickness, mm & 0.381 \\
\hline Tube \& Facesheet Material & AL 6061 \\
\hline
\end{tabular}

An optimization study around panel thickness was considered. For reducing facesheet thicknesses the area increases to offsed reduced fin efficiencies. The initial optimization is done with tube spacing of $0.125 \mathrm{~m} \mathrm{(4.94}$ inches), with 16 tubes and $\varepsilon=0.9$.

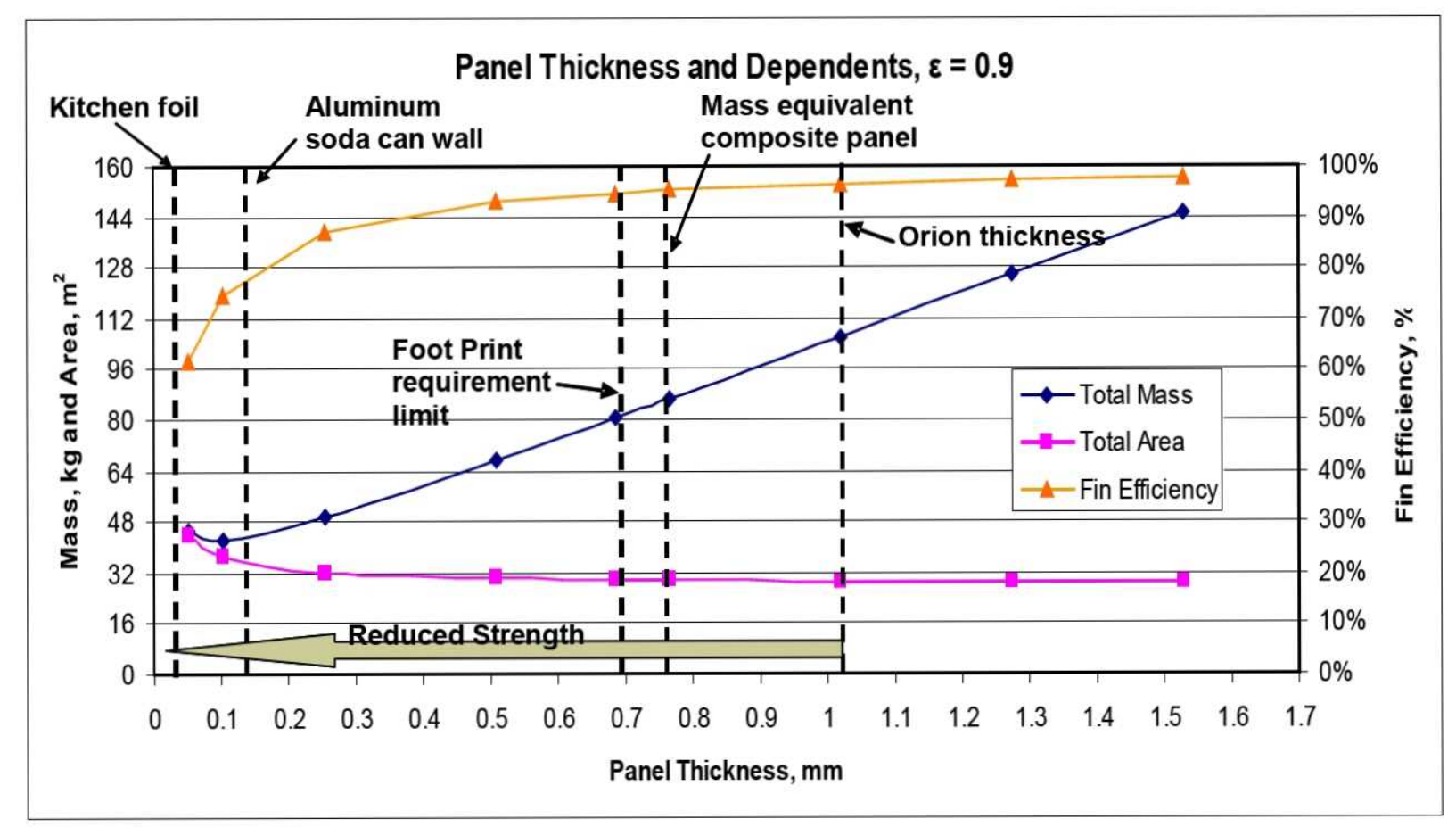

Figure 16. Solid Panel, $\varepsilon=0.9,16$ Tubes, Facesheet Thickness relations

After reviewing Figure 17 from a mass optimization point of view, a thinner facesheet would be of great benefit. An aluminum honeycomb panel must be used to get these thinner facesheets for structural reasons. Figure 18 shows the facesheet thickness optimization for an aluminum honeycomb panel. The panel thickness used is the combined thickness of both facesheets and a modified conductivity is used to account for the aluminum core. 


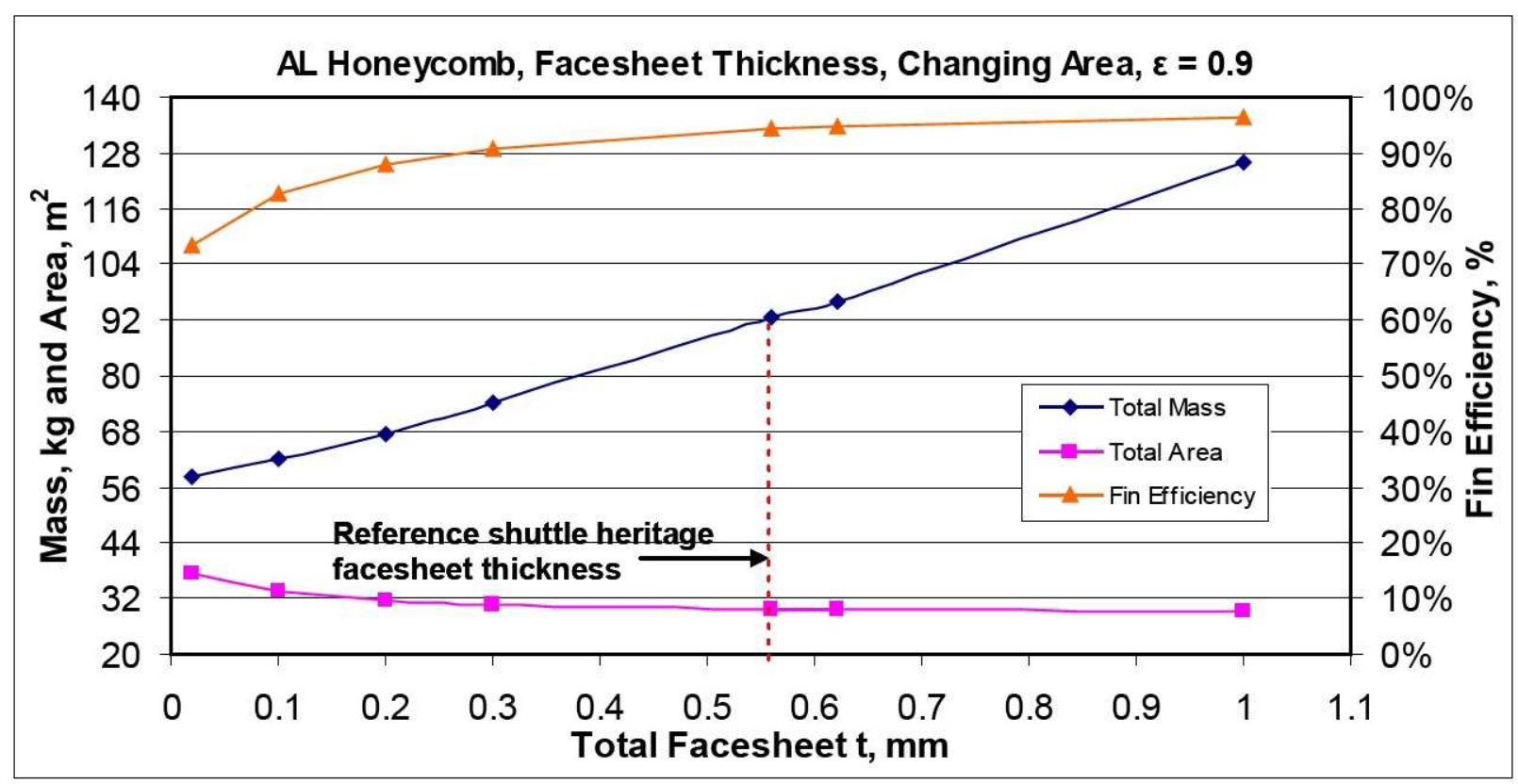

Figure 17. Aluminum Honeycomb Panel Facesheet Optimization, $\varepsilon=0.9$

For a point of reference, a shuttle heritage design has two $0.28 \mathrm{~mm}(0.011 \mathrm{in})$ facesheets for a total thickness of $0.56 \mathrm{~mm}(0.022 \mathrm{in})$. A solution for this thickness is displayed in Figure 18, with a resulting mass of $92 \mathrm{~kg}$. The required area for this thickness also corresponds to the given area goal. The plot reveals that significant mass savings could be achieved with thinner facesheets, but may again be limited by structural requirements.

Tube spacing optimization was considered by determining effect of tube spacing on system mass by adjusting facesheet thickness to meet the given the suggested foot print requirement. Figure 9 shows this optimization for both the solid and aluminum honeycomb panels that have a maximum emissivity of 0.9 .

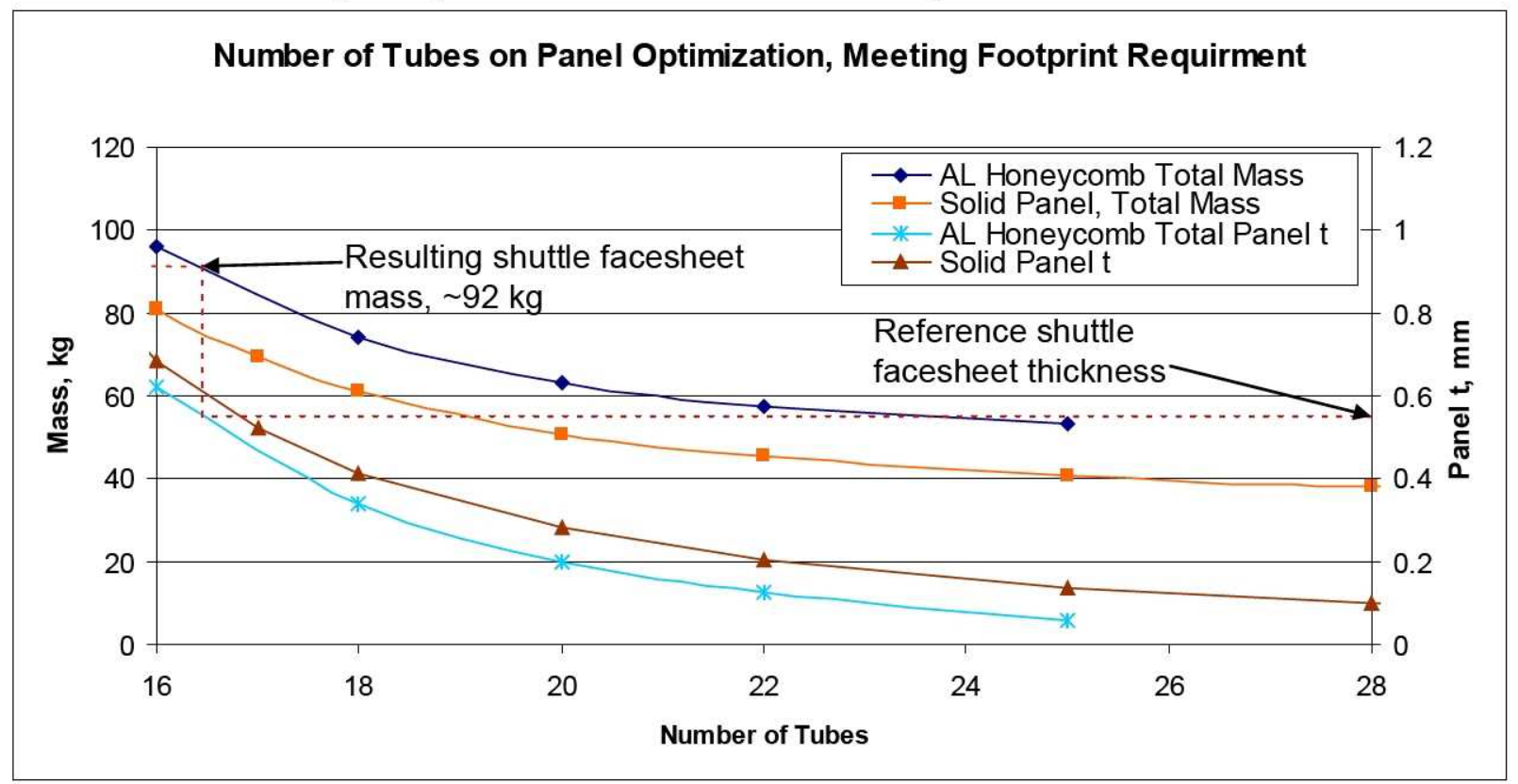

Figure 18. Tube Number Optimization Given Foot Print Requirement with an Emissivity of 0.9, Solid and Aluminum honeycomb Panel

Figure 19 clearly shows that considerable mass can be saved by increasing tube quantity and decreasing the facesheet thickness. Decreased facesheet thickness is particularly noticeable in the aluminum honeycomb panel as 
the facesheet thickness goes to zero at 28 tubes. This means that at 28 tubes the conductivity of the honeycomb is sufficient to transfer heat but is an infeasible design as there would be no facesheets to provide rigidity. Figure 20 shows the results of the lower maximum emissivity of 0.7 (previous graphs showed high $\varepsilon$ max $=0.9$ ). The plot shows combined results for both solid and aluminum honeycomb panels for a fixed tube spacing of 0.1 meters and varying panel thickness.

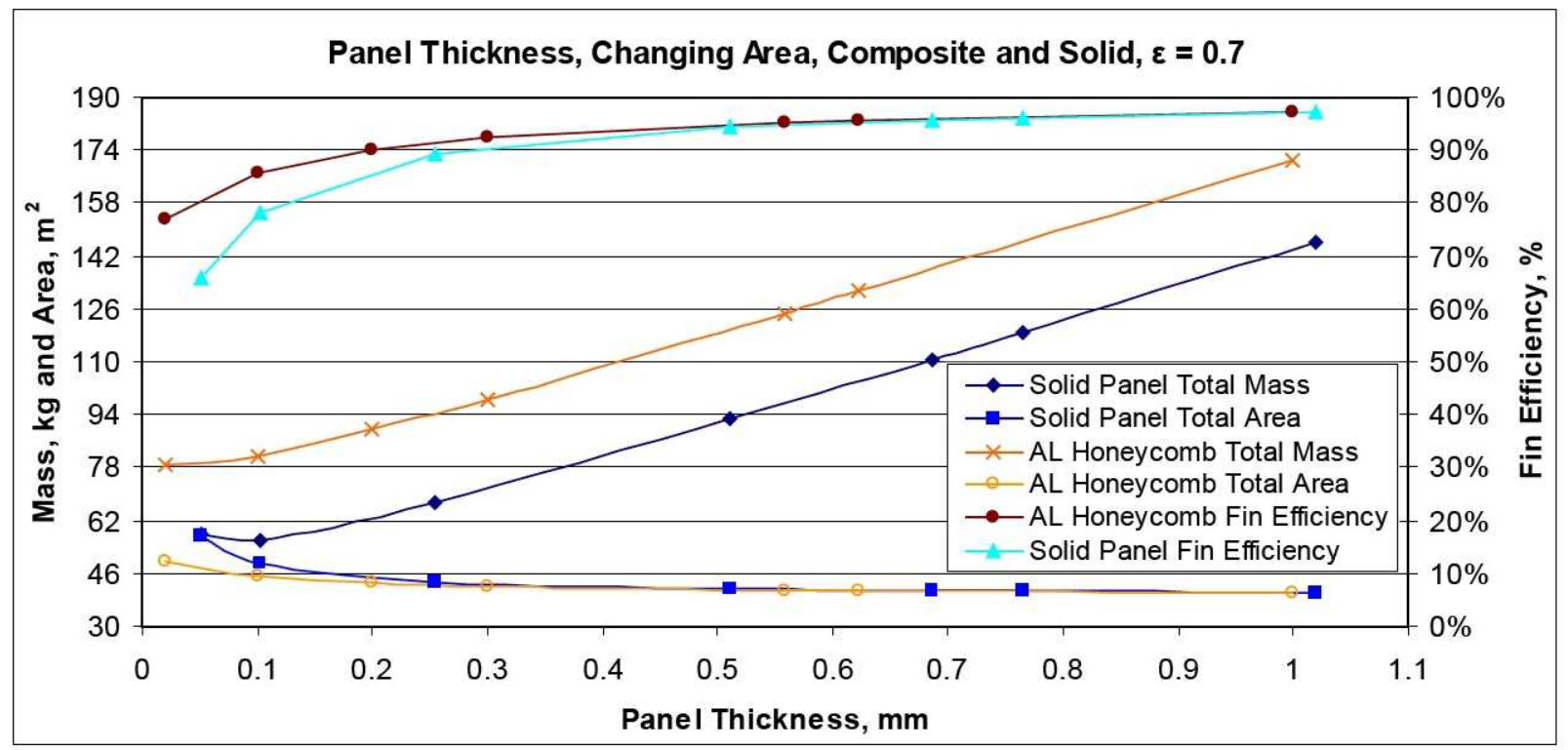

Figure 20. Solid and Aluminum honeycomb Panel Facesheet Optimization, $\varepsilon=0.7,20$ tubes

As expected, Figure 20 shows that the low maximum emissivity panel requires more area and mass than the higher maxumim emissivity. For the design requirements, the e $=0.7$ panel yields around $6.3 \%$ more mass than simply scaling by its emissivity would predict due to an increase in the equivalent sink temperature.

From the preceding tube optimization analysis, it can be seen that it is difficult do design a radiator to meet the Altair requirements based solely on mass optimization. Structural considerations not only drive the design toward an aluminum honeycomb panel but will require a structurally based facesheet thickness limit as the thermally based analysis otherwise drives this thickness towards zero. Comparing various solutions at the 0.9 maximum emissivity which meets the footprint goal, $2.0 \mathrm{~m} \times 3.7 \mathrm{~m}$, a shuttle based electrochromics design would be $92 \mathrm{~kg}$ (which is similar to a 16 tube design), and a more mass optimized 25 tube radiator with much thinner facesheets is $53 \mathrm{~kg}$. This mass of this solution can be broken down to $17.82 \mathrm{~kg}$ of electrochromics, $4.83 \mathrm{~kg}$ of facesheet mass, $18.86 \mathrm{~kg}$ from the core, $8.94 \mathrm{~kg}$ of facesheet tubes, and $2.59 \mathrm{~kg}$ of manifolds.

Parallel flow does not result in significant performance improvement. A $0.07 \%$ heat rejection improvement was seen but other operational considerations were deemed to out weigh this small gain.

\section{Emissivity Ratio Optimization, Cold Case}

Figure 11 shows how the emissivity ratio changes with area solutions that meet the given heat rejection requirements. The plots reveal that for a given high emissivity, the resulting emissivity ratio is a linear function of area. 


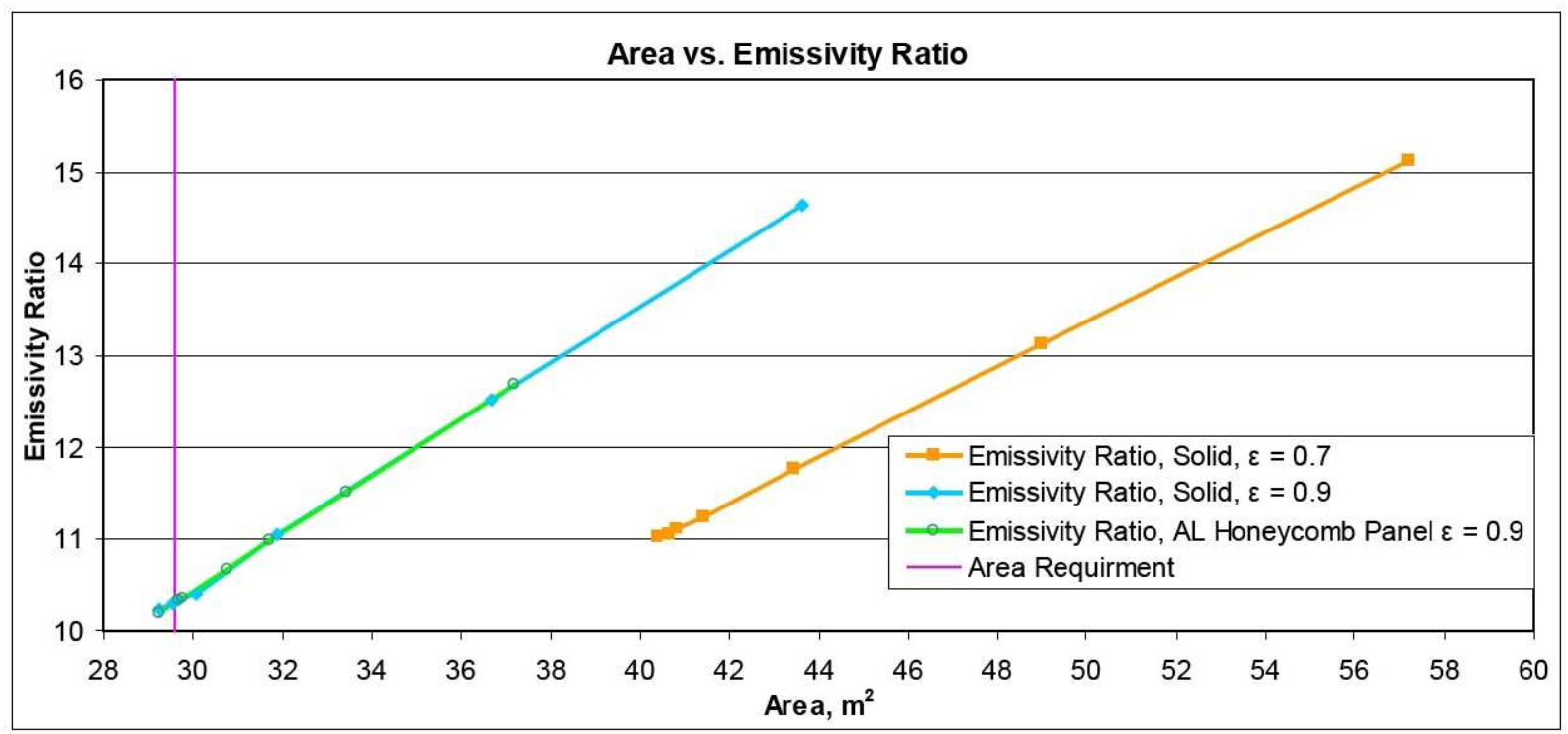

Figure 9. Panel Area vs. Emissivity Ratios of Panel Configurations That Meet Given Heat Rejection Requirements

The linear relationship shown between emissivity ratio and area holds for either 25 or 16 tube panels given a particular high emissivity. The 16 tube emissivity ratio is identical in the 25 tube emissivity ratio because they share the same fin efficiency. At the given area requirement of $29.9 \mathrm{~m} 2$ the required emissivity ratio is 10.3 . Figure 21 also shows that while mass optimization alone drives towards larger areas, emissivity ratio alone makes minimized area desirable. In general, emissivity ratios for any radiator designed for Altair requirements is shown to be between 10 and 12. Being that this range in emissivity ratios is not currently nor expected to be with in the range of electrochromic device capability other technologies will have to be used with electrochromics. That is why pairing electrochromics with the use of a bypass loop and/or RHX will be explored further.

Due to structural concerns with the 25 tube configuration and a desire to base the design on a heritage design, a configuration based on the shuttle radiator design with 16 tubes is carried forward in the remainder of the analysed configurations. Table 8 lists the important parameters in the shuttle 16 tube configuration that will be used from this point on.

Table 8. Panel Configurations

\begin{tabular}{|l|r|}
\hline Tube number & 16 \\
\hline Total Facesheet thickness, mm (in) & $0.559(0.022)$ \\
\hline Aluminum honeycomb k, W/m/K (btu/hr/in/R) & $173.53(8.36)$ \\
\hline Width, m (in) & $2.00(78.74)$ \\
\hline Length, m (in) & $3.74(147.25)$ \\
\hline Total Area, m2 (ft2) & $29.70(80.5)$ \\
\hline Tube Wall Thickness mm (in) & $0.71(0.028)$ \\
\hline High Emissivity & 0.9 \\
\hline Facesheet Material & AL 2024-T81 \\
\hline Total Hot Mass, kg & 96.7 \\
\hline
\end{tabular}

Figure 22 shows the resulting data for the shuttle configuration with bypass and RHX. Figure 22 shows the emissivity ratio and mass vs. the radiator return temperature, it also shows the ratio of mass flow going through the bypass loop as data labels on the emissivity ratio lines. In each case, the mixed return temperature of the fluid returning to the vehicle is always $283 \mathrm{~K}$. The graph shows the results of varying the bypass ratio, which is the fraction of the mass flow that is shunted around the radiator to the total system mass flow. The figures also show the results of using a RHX on its own (bypass ratio $=0$ ) and in conjunction with the bypass loop, bypassing radiator panels and RHX. 


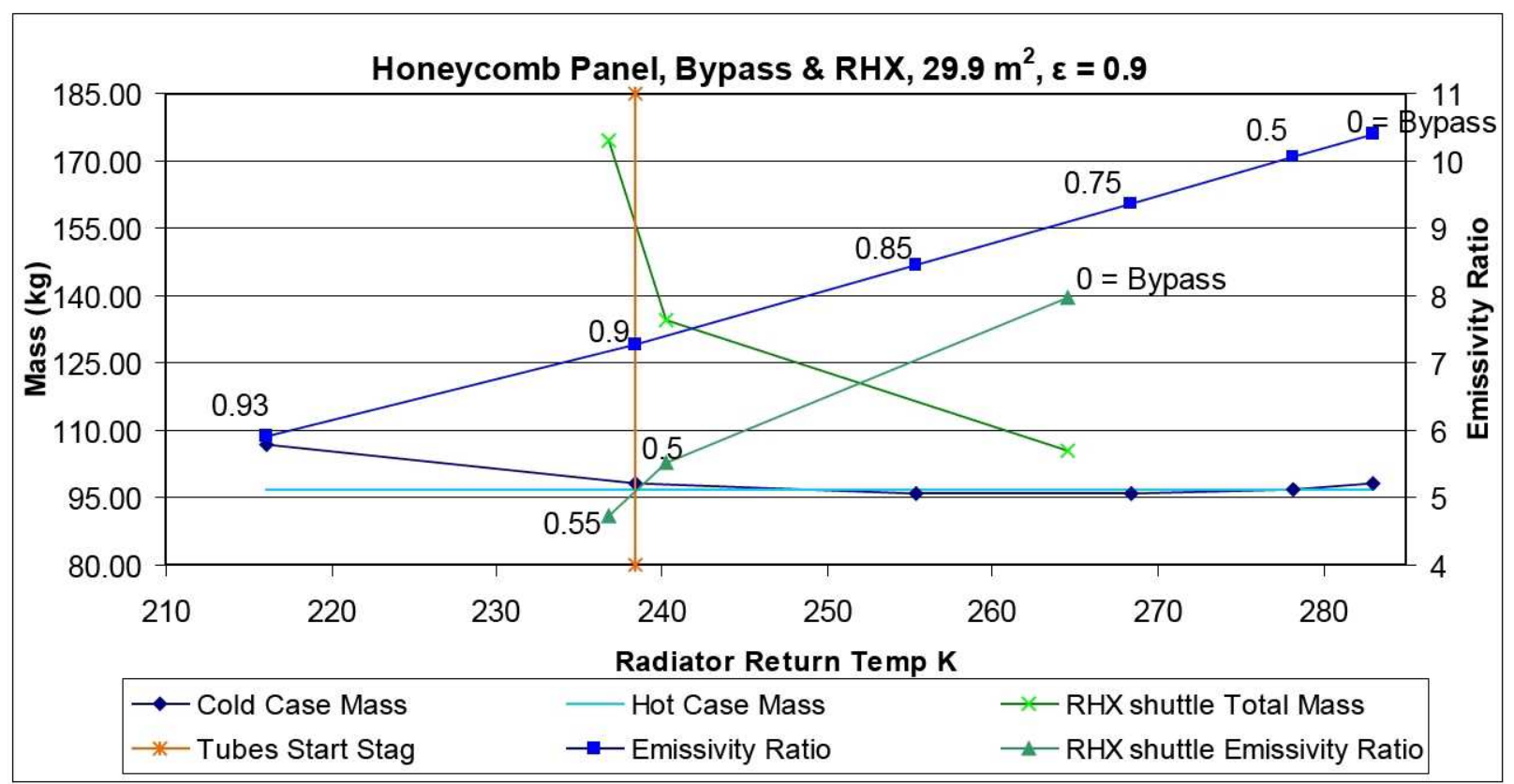

Figure 22. Bypass and RHX Comparison of Mass and Emissivity Ratio vs. Temperature

Figure 22 shows "Cold Case Mass" data, "Hot Case Mass" data, and emissivity ratios. The "Hot Case Mass" data represents the mass required to meet the requirements of the environmental hot case. The cold case mass changes mostly due to changes in the diameter of the tubes on the radiator. At each data point, the diameter of the tubes is varied to meet pressure limits as viscosity increases, resulting in a change in total fluid and tube mass. There is a smaller effect from the change in fluid density with change in temperature. Since a radiator must work in either case, the higher of the reported cold case mass and the hot mass case would be required for the system. The cold case mass is greater than the hot case when the effect of reduced flow velocity at a given bypass ratio on pressure drop is outweighed by increased viscosity at the resultant colder fluid temperature. In these cases, the tube diameter required to maintain the pressure drop in the cold case is higher than the hot full flow case. The required emissivity ratio is the maximum emissivity of 0.9 from the hot case divided by the emissivity needed to meet the mixed cabin return temperature under the given cold case conditions. Figure 22 reveals that the emissivity ratio is linear with return temperature for bypass flow.

The reported stagnation line corresponds to the temperature below which a verification Thermal Desktop model begins to show unequal flow in the tubes. The stagnation line only applies to the bypass results.

The emissivity ratio for bypass is 7.3 at the stagnation line which would result in a system with a mass of $98 \mathrm{~kg}$. Stagnation was noted in the RHX configuration at mass flow rates lower and return temperatures colder than is reported here.. The lowest emissivity ratio then for the RHX is 4.7 which results in a mass of $174 \mathrm{~kg}$.

One interesting result is that the RHX yields a heavier system for the same required emissivity ratio than just a bypass loop. This occurs since for a given mass flow rate, the average fluid temperature is reduced by the RHX, which in turn increases fluid viscosity, resulting in larger tubes to meet the pressure drop requirement. A RHX can be used to drive down the required emissivity ratio of the devices, but with a mass penalty.

Figure 23 shows that for maximum emissivity values of 0.7 and 0.9 there is an approximately constant percentage difference between emissivity ratios. (Note that the area requirement for a $\varepsilon \max =0.7$ is larger to meet requirements). Thus data in Figure 22 can be paired with the required full flow emissivity ratio data found in the Panel Area vs. Emissivity Ratios graph Figure 21, to yield the required emissivity ratio for a given area, high emissivity, and allowable radiator return temperature. 


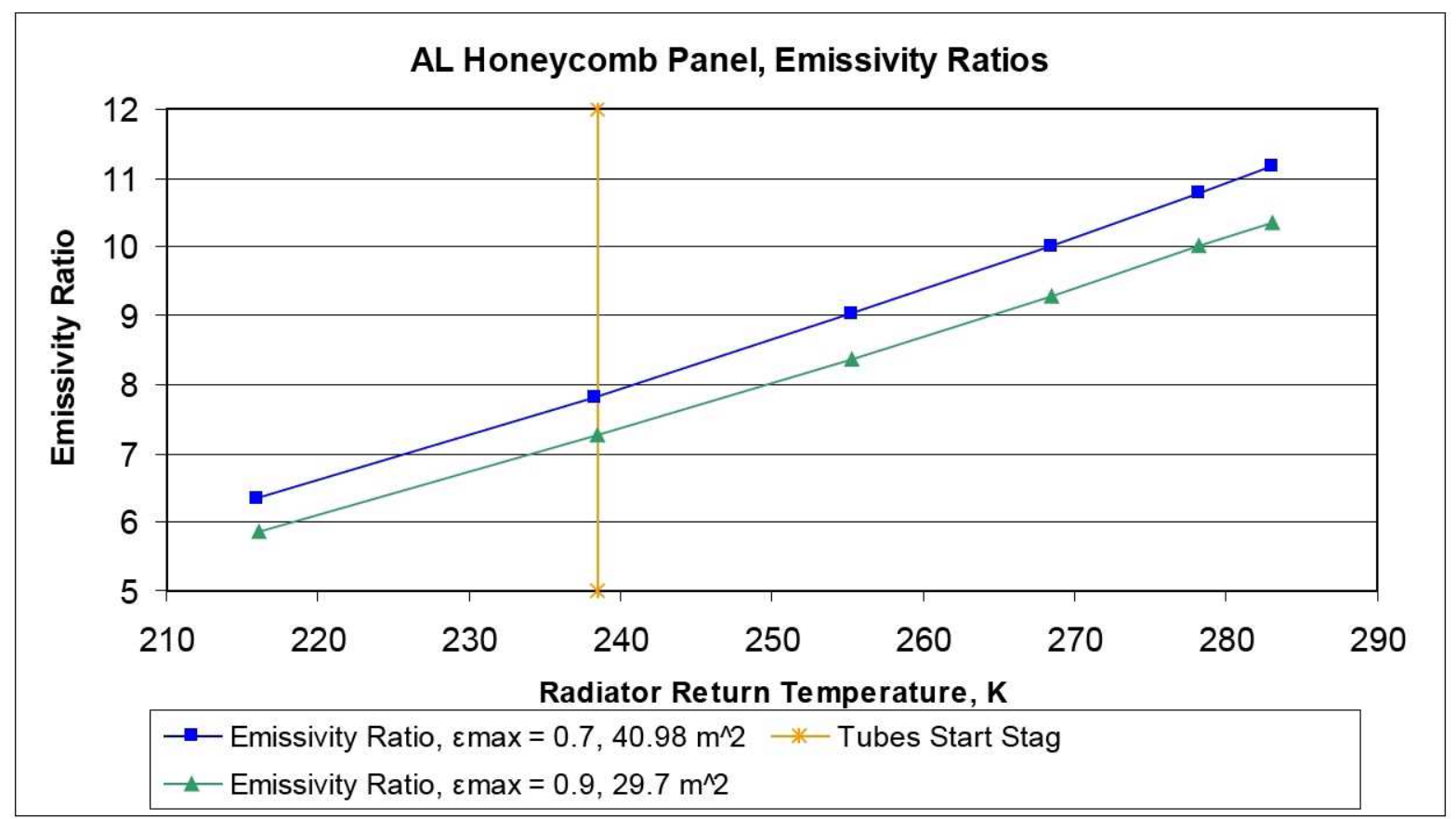

Figure 10. Aluminum honeycomb Panel Emissivity Ratio vs. Radiator Return Temperature and Comparison of Emissivity Ratio difference between a High and Low Emissivity Case

For example one could determine the emissivity ratio required for a 0.7 maximum emissivity panel that has an area of $43.5 \mathrm{~m} 2$ and an allowable return temperature of $255 \mathrm{~K}$. The full flow ( $283 \mathrm{~K}$ return temp) value at $43.5 \mathrm{~m} 2$ for a maximum emissivity of 0.7 from Figure 11 is 11.8 . The emissivity ratio of 11.8 is $12.4 \%$ higher then the full flow case with a max emissivity of 0.9 and an area of $29.7 \mathrm{~m} 2$. The $29.7 \mathrm{~m} 2 \mathrm{\varepsilon max}=0.9$ case shown in Figure 23 has an emissivity ratio of 10.34 at full flow so $1-(10.34 / 11.8)=12.4 \%$. Looking at Figure 23 and applying the $12.4 \%$ to the $255 \mathrm{~K}$ return temperature point (that has a max emissivity of 0.9 ) the resulting emissivity ratio for the $0.7 \max$ emissivity case with a return temperature of $255 \mathrm{~K}$ is $9.41(8.37 * 1.124=9.41)$. This method was verified by calculating the $40.98 \mathrm{~m} 2$ at the 0.7 case and comparing it to what is shown in Figure 23.

During this study it was discovered that actual solar absorption values are predicted to be higher then originally thought, 0.3 to 0.35 rather than 0.25 as was employed in all of the data up to this point. Table 9 shows that the sink temperature increases with an increase in solar absorbtivity, an effect that is similar to a decrease in emissivity.

Table 9. Sink Temperatures

\begin{tabular}{|c|r|r|}
\hline $\mathrm{K}$ & $\varepsilon=0.9$ & $\varepsilon=0.7$ \\
\hline$\alpha=0.25$ & 232 & 241 \\
\hline$\alpha=0.3$ & 238 & 248 \\
\hline$\alpha=0.35$ & 244 & 255 \\
\hline
\end{tabular}

The effect of changing the solar absorbtivity on the flow emissivity ratio is shown in Figure 24. 


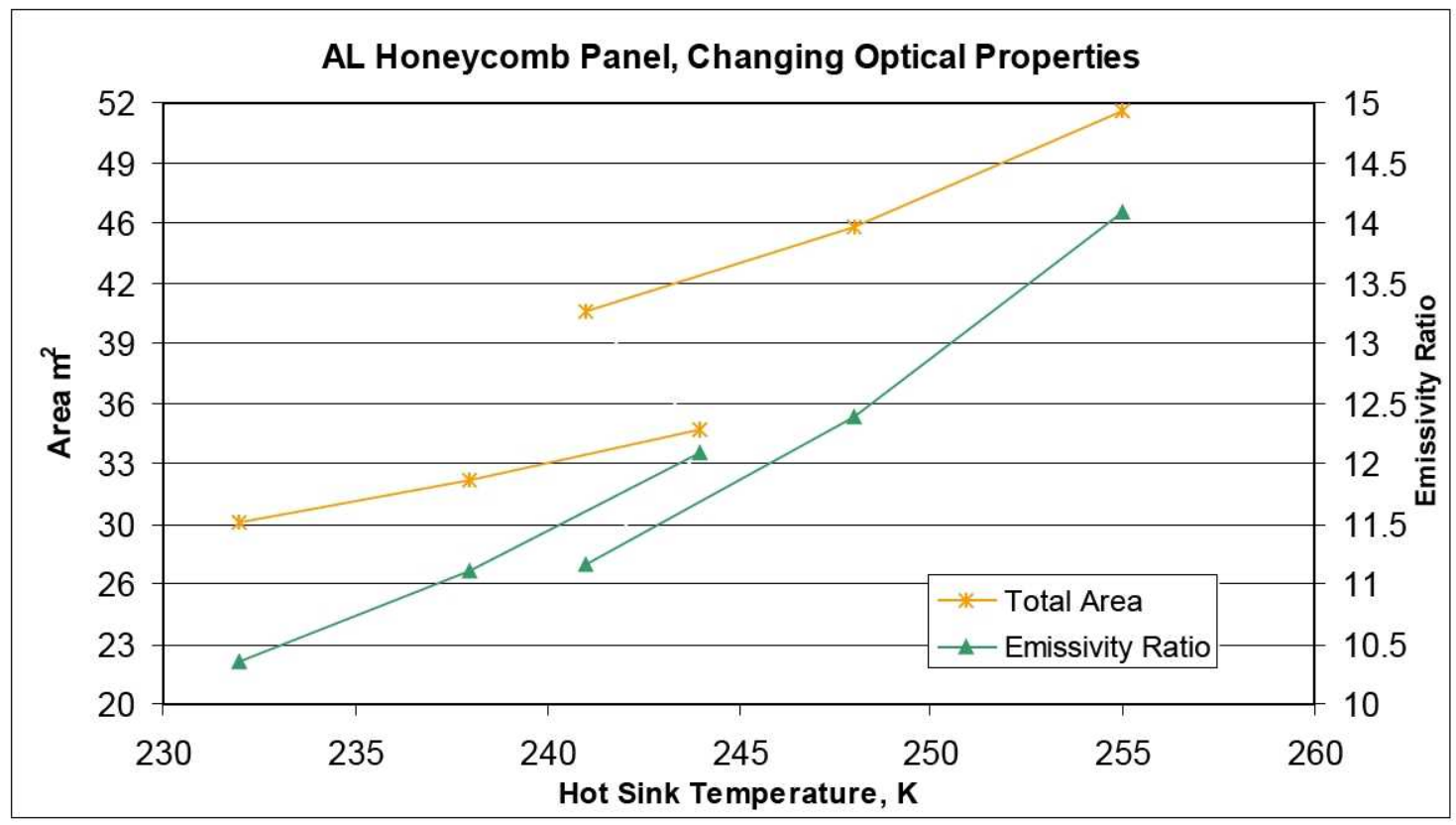

Figure 11 Hot Sink vs. Area and Emissivity Ratio

In Figure 24, the change in max emissivity results in an immediate jump up in area because of this the first line on the chart has the higher emissivity and the right most line as the lower emissivity. Table 3 can be used to look up specific optical properties for the given sink temperature.

\section{Conclusion}

A 16 tube aluminum honeycomb radiator based on shuttle heritage designs has a mass of $96.7 \mathrm{~kg}$. Further mass could be removed from the system by increasing the number of tubes and reducing the thickness of the facesheet. A 25 tube solution with equivalent performance and area would weigh $53 \mathrm{~kg}$. Structural limitations will require consideration in order to determine a true mass optimized system.

Variation of surface high limit emissivity from 0.9 to 0.7 reveals that a 0.7 emissivity case can not be developed for any radiator design within the foot print goal. The results also show that the required area and mass scales inversely proportionally with emissivity plus a small penalty.

Without stagnation, 7.28 is the best emissivity ratio obtainable for masses comparable to the full flow configuration, $98.2 \mathrm{~kg}$ for 16 tubes. A significant finding is that the RHX results in much more mass than the bypass loop configuration for the same required emissivity ratio, but it can allow the radiator to go to an emissivity ratio as low as 4.7 without stagnation at the expense of mass.

\section{Appendix}

The properties used in the Excel are given in Table 10 with English units a graph of the properties of PGW is given in Figure 15. 


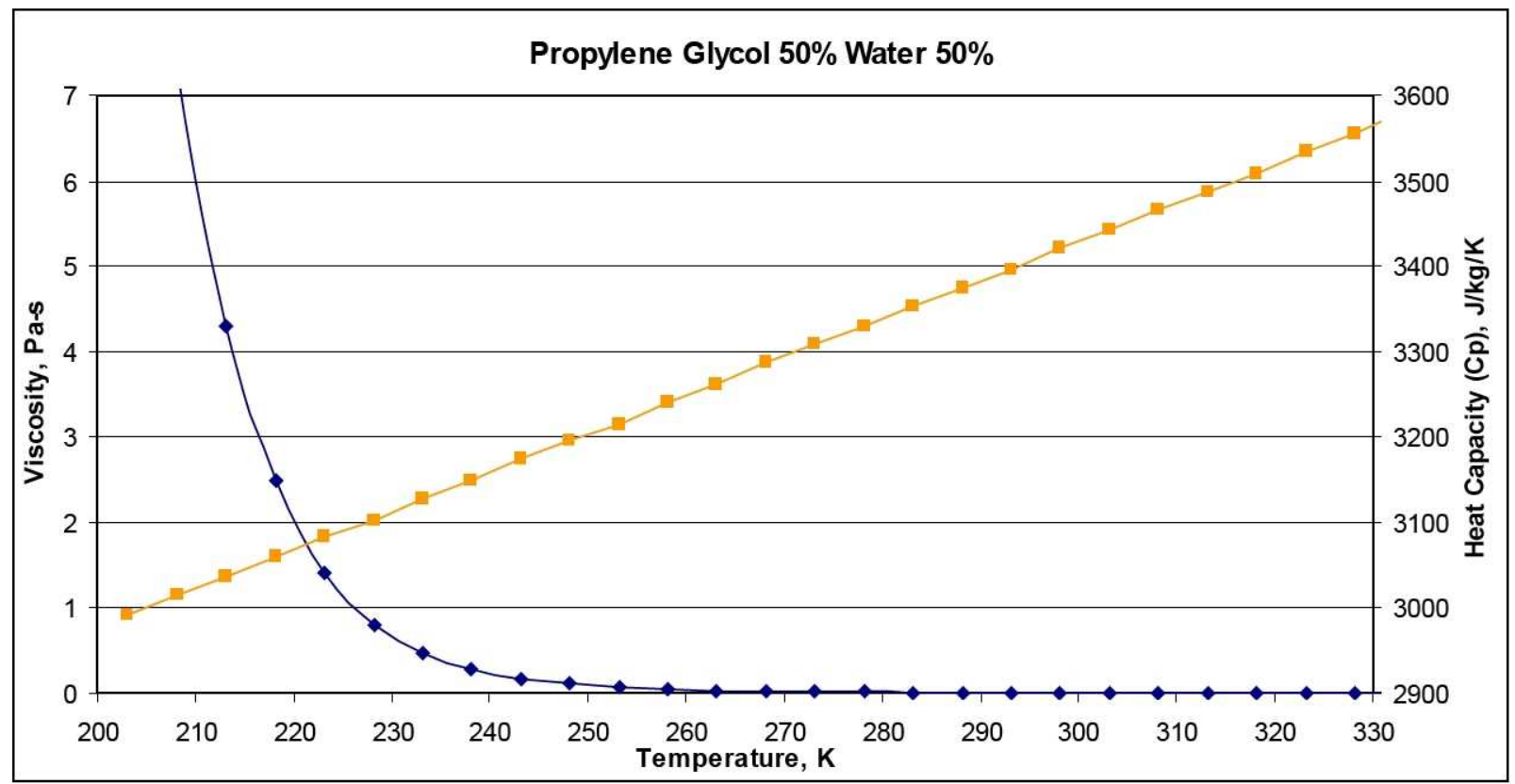

Figure 12. PGW Properties

Table 10. PGW Property Equations Used

\begin{tabular}{|l|l|r|r|r|r|r|r|r|}
\hline & Temperature Range & T6 & T5 & T4 & T3 & T2 & T1 & T0 \\
\hline $\begin{array}{l}\text { Specific Heat, } \\
\text { BTU/lbm-R }\end{array}$ & Down to 198.4 K & & & & & & 0.0006 & 0.7713 \\
\hline $\begin{array}{l}\text { Thermal } \begin{array}{l}\text { Conductivity, } \\
\text { BTU/hr-in-R }\end{array} \\
\text { Down to 198.4 K }\end{array}$ & & & & & & & \\
\hline $\begin{array}{l}\text { Viscosity Hot, } \\
\text { lbm/ft/s }\end{array}$ & Down to 243 K & & & & & & & \\
\hline $\begin{array}{l}\text { Viscosity Cold, } \\
\text { lbm/ft/s }\end{array}$ & 198.4 K to $258 \mathrm{~K}$ & $\begin{array}{r}4.0 \mathrm{E}- \\
12\end{array}$ & $\begin{array}{r}-5.0 \mathrm{E}- \\
10\end{array}$ & $\begin{array}{r}9.0 \mathrm{E}- \\
09\end{array}$ & $\begin{array}{r}-9.0 \mathrm{E}- \\
08\end{array}$ & $\begin{array}{r}5.0 \mathrm{E}- \\
05\end{array}$ & \\
\hline $\begin{array}{l}\text { Density, } \\
\text { lbm/ft3 }\end{array}$ & Down to $198.4 \mathrm{~K}$ & & & & & & -0.0023 & 0.015 \\
\hline
\end{tabular}

\section{Acknowledgments}

The authors of this paper would like to acknowledge Prasanna Chandrasekhar and his team at Ashwin Ushas Corporation for providing electrochromic test articles. Acknowledgments would also like to be given to Christie Iacomini and Barry Finger at Pargaon Space Development Corporation

\section{References}

Books

1 Gilmore, David G., Spacecraft Thermal Control Handbook Volume I: Fundamental Technologies, 2nd Edition, The Aerospace Press, El Segundo, California, 2002, pp. 405-418.

2 Siegel, Robert, and Howell, John, Thermal Radiation Heat Transfer, 4th Edition, Taylor \& Francis, New York, 2002, pp. 343-344, Equation 9.8 . 